\title{
The Id, the Ego, and Equal Protection: Reckoning with Unconscious Racism
}

\author{
Charles R. Lawrence III*
}

\section{Prologue}

It is 1948. I am sitting in a kindergarten classroom at the Dalton School, a fashionable and progressive New York City private school. My parents, both products of a segregated Mississippi school system, have come to New York to attend graduate and professional school. They have enrolled me and my sisters here at Dalton to avoid sending us to the public school in our neighborhood where the vast majority of the students are black and poor. They want us to escape the ravages of segregation, New York style.

It is circle time in the five-year old group, and the teacher is reading us a book. As she reads, she passes the book around the circle so that each of us can see the illustrations. The book's title is Little Black Sambo. Looking back, I remember only one part of the story, one illustration: Little Black Sambo is running around a stack of pancakes with a tiger chasing him. He is very black and has a minstrel's white mouth. His hair is tied up in many pigtails, each pigtail tied with a different color ribbon. I have seen the picture before the book reaches my place in the circle. I have heard the teacher read the "comical" text describing Sambo's plight and have heard the laughter of my classmates. There is a knot in the pit of my stomach. I feel panic and shame. I do not have the words to articulate my feelings-words like "stereotype" and "stigma" that might help cathart the shame and place it outside of me where it began. But I am slowly realizing that, as the only black child in the circle, I have some kinship with the tragic and ugly hero of this story-that my classmates are laughing at me as well as at him. I wish I could laugh along with my friends. I wish I could disappear.

I am in a vacant lot next to my house with black friends from the neighborhood. We are listening to Amos and Andy on a small radio and laughing uproariously. My father comes out and turns off the radio. $\mathrm{He}$ reminds me that he disapproves of this show that pokes fun at $\mathrm{Ne}-$ groes. I feel bad-less from my father's reprimand than from a sense

* Professor of Law, Stanford University. B.A., Haverford College, 1965; J.D., Yale Law School, 1969. My thanks go to Professors Stephen Arons, Derrick Bell, Richard Delgado, and Thomas Grey for their helpful comments, and to Bryan Ford, Julie Cape, and Hillary Kramer for their research assistance. 
that I have betrayed him and myself, that I have joined my classmates in laughing at us.

I am certain that my kindergarten teacher was not intentionally racist in choosing Little Black Sambo. I knew even then, from a child's intuitive sense, that she was a good, well-meaning person. A less benign combination of racial mockery and profit motivated the white men who produced the radio show and played the roles of Amos and Andy. But we who had joined their conspiracy by our laughter had not intended to demean our race.

A dozen years later I am a student at Haverford College. Again, I am a token black presence in a white world. A companion whose face and name I can't remember seeks to compliment me by saying, "I don't think of you as a Negro." I understand his benign intention and accept the compliment. But the knot is in my stomach again. Once again, I have betrayed myself.

This happened to me more than a few times. Each time my interlocutor was a good, liberal, white person who intended to express feelings of shared humanity. I did not yet understand the racist implications of the way in which the feelings were conceptualized. I am certain that my white friends did not either. We had not yet grasped the compliment's underlying premise: To be thought of as a Negro is to be thought of as less than human. We were all victims of our culture's racism. We had all grown up on Little Black Sambo and Amos and Andy.

Another ten years pass. I am thirty-three. My daughter, Maia, is three. I greet a pink-faced, four-year old boy on the steps of her nursery school. He proudly presents me with a book he has brought for his teacher to read to the class. "It's my favorite," he says. The book is a new edition of Little Black Sambo.

\section{INTRODUCTION}

This article reconsiders the doctrine of discriminatory purpose that was established by the 1976 decision, Washington $v$. Davis. ${ }^{1}$ This now well-established doctrine requires plaintiffs challenging the constitutionality of a facially neutral law to prove a racially discriminatory purpose on the part of those responsible for the law's enactment or administration. ${ }^{2}$

1. 426 U.S. 229 (1976).

2. E.g., Hunter v. Underwood, 471 U.S. 222 (1985). In Hunter, the Court determined that a provision in the Alabama Constitution disenfrachising persons convicted of crimes involving moral turpitude violated the equal protection clause. Even though the provision was racially neutral on its face, its original enactment was motivated by a desire to discriminate against blacks, and it had had a racially discriminatory impact since its adoption. The Court reaffirmed the doctrine that "[p]roof of racially discriminatory intent or purpose is required to show a violation of the Equal Protection Clause." Id. at 226 (citing Village of Arlington Heights v. Metropolitan Hous. Dev. Corp., 429 U.S. 252, 264-65 (1977)). A LEXIS search in October of 1986 found 38 cases that cite Davis for the principle that proof of discriminatory 
Davis has spawned a considerable body of literature treating its merits and failings. ${ }^{3}$ Minorities and civil rights advocates have been virtually unanimous in condemning Davis and its progeny. ${ }^{4}$ They have been joined by a significant number of constitutional scholars who have been equally disapproving, if more restrained, in assessing its damage to the cause of equal opportunity. ${ }^{5}$ These critics advance two principal arguments. The first is that a motive-centered doctrine of racial discrimination places a very heavy, and often impossible, burden of persuasion on the wrong side of the dispute. 6 Improper motives are easy to hide. And because behavior results from the interaction of a multitude of motives, governmental officials will always be able to argue that racially neutral considerations prompted their actions. Moreover, where several decisionmakers are involved, proof of racially discriminatory motivation is even more difficult.

The second objection to the Davis doctrine is more fundamental. It argues that the injury of racial inequality exists irrespective of the decisionmakers' motives. Does the black child in a segregated school experience less stigma and humiliation because the local school board did not consciously set out to harm her? Are blacks less prisoners of the ghetto because the decision that excludes them from an all-white neighborhood was made with property values and not race in mind? Those who make this second objection reason that the "facts of racial inequal-

intent is necessary when disproportionate impact results from facially neutral governmental action.

3. See, e.g., Bell, Foreword: Equal Employment Law and the Continuing Need for Self-Help, 8 Loy. U. CHI. L.J. 681 (1977); Freeman, Legitimizing Racial Discrimination Through Antidiscrimination Law: A Critical Review of Supreme Court Doctrine, 62 Mins. L. REv. 1049 (1978); Karst, Foreword: Equal Citizenship Under the Fourteenth Amendment, 91 HaRv. L. REv. 1 (1977); Reiter, Compensating for Race or National Origin in Employment Testing, 8 Loy. U. CHI. L.J. 687 (1977); Schwemm, From Washington to Arlington Heights and Beyond: Discriminatory Purpose in Equal Protection Litigation, 1977 U. ILL. L.F. 961 ; see also Colloquium on Legislative and Administrative Motivation in Constitutional Law, 15 SAN DIEGo L. REv. 925 (1978) (colloquium containing ten articles discussing motivation theory).

4. See Lewin, Trivializing Discrimination, New Republic, Apr. 2, 1977, at 19; The Court's Purpose - and Effect, N.Y. Times, Jan. 15, 1977, at 20, col. 1; see also Dreyfus, The New Racism, BlaCk ENTERPRISE, Jan. 1, 1978, at 41; Hall, Exclusionary Zoning-City of Memphis v. Greene, 8 BLACK L.J. 138 (1983) (student author); Perka, Racially Disproportionate Impact of Facially Neutral Practices-Ihat Aptroach Under 42 U.S.C. Settions 1981 and 1982?, 1977 DukE L.J. 1267 (student author); Schnapper, Two Categories of Discriminatory Intent, 17 HARv. C.R.-C.L. L. REv. 31 (1982); note 3 supra.

5. See Karst, The Costs of Motive-Centered Inquiry, 15 San Dirgo L. Rev. 1163 (1978); Schwemm, supra note 3; see also Eisenberg, Disproportionate Impact and Illicit Motive: Theories of Constitutional Adjudication, 52 N.Y.U. L. REv. 36 (1977); Perry, The Disproportionate Impact Theory of Racial Discrimination, 125 U. PA. L. REv. 540 (1977); Weinzweig, Discriminatory Impact and Intent Under the Equal Protection Clause: The Supreme Court and the Mind-Body Problem, 1 Law \& INEQUALTY 277 (1983).

6. Professor Ely, the motive test's first advocate, recently expressed concern that the effect of the Supreme Court's use of the test "has been in each case to deny the constitutional claim." Ely, The Centrality and Limits of Motivation Analysis, 15 SAN Diego L. REv. 1155, 1160 (1978); see also Karst, supra note 5, at 1165; Simon, Racially Prejudiced Governmental Actions: $A$ Motivation Theory of the Constitutional Ban Against Racial Discrimination, 15 SAN Diego L. Rev. $1041,1097-107$ (1978). 
ity are the real problem."7 They urge that racially disproportionate harm should trigger heightened judicial scrutiny without consideration of motive. ${ }^{8}$

Supporters of the intent requirement are equally adamant in asserting the doctrine's propriety. ${ }^{9}$ They echo the four main arguments that the Court itself set forth in Davis: (1) A standard that would subject all governmental action with a racially disproportionate impact to strict judicial scrutiny would cost too much; such a standard, the Court argues, would substantially limit legitimate legislative decisionmaking and would endanger the validity of a "whole range of [existing] tax, welfare, public service, regulatory and licensing statutes"; 10 (2) a disproportionate impact standard would make innocent people bear the costs of remedying a harm in which they played no part; ${ }^{11}$ (3) an impact test would be inconsistent with equal protection values, because the judicial decisionmaker would have to explicitly consider race; ${ }^{12}$ and (4) it would be inappropriate for the judiciary to choose to remedy the racially disproportionate impact of otherwise neutral governmental actions at the ex-

7. Karst, supra note 5 , at 1165 . A related argument notes that prior intentional discrimination can produce current deprivation even without a present intent to discriminate. Washington v. Davis itself provides an excellent example. In Davis, blacks' poor performance on the civil service written exam could be traced directly to the history of intentional discrimination in the city's segregated school system. See Lawrence, "Justice" or "Just Us": Racism and the Role of Ideology (Book Review), 35 STAN. L. REv. 831, 849 n.69 (1983). Furthermore, the "disproportionate absence of minorities from certain positions-whether or not itself the result of racial discrimination-may produce discrimination in other areas." Brest, Foreword: In Defense of the Antidiscrimination Principle, 90 Harv. L. Rev. 1, 43 (1976). Brest notes that the Court's special concern for minority voting rights reflects the belief that uneven voting power, even if it results from unintentional acts, produces discrimination in other areas and justifies judicial resort to a pure impact test. Id. at 43,44 .

8. See, e.g., Eisenberg, supra note 5, at 57 (proposing a "causation" theory under which strict scrutiny would be triggered, regardless of motive, whenever disproportionate impact was "reasonably attributable to race").

9. See Bennett, "Mere" Rationality in Constitutional Law: Judicial Review and Democratic Theory, 67 Calif. L. REv. 1049, 1076 (1979); Ely, Legislative and Administrative Motivation in Constitutional Law, 79 YALE L.J. 1205 (1970); Miller, Proof of Racially Discriminatory Purpose Under the Equal Protection Clause, 12 HARv. C.R.-C.L. L. Rev. 725, 738-39 (1977) (student author).

10. Washington v. Davis, 426 U.S. 229, 248 \& n.14 (1976) (citing Goodman, De Faclo School Segregation: A Constitutional and Empirical Analysis, 60 CALIF. L. REv. 275, 300 (1972)); see also Dandridge v. Williams, 397 U.S. 471 (1970) (arguing constitutionality of limiting welfare to AFDC recipients relative to what other equally needy families receive); Ferguson v. Skrupa, 372 U.S. 726, 726-27 (1963) (upholding state's power to limit "the business of debt adjusting" to those in "the lawful practice of law"); Brest, supra note 7, at 11, 29.

11. The Court has noted that invalidating a decision because of its disproportionate impact would often be a remedy disproportionate to the decisionmakers' presumably racially neutral act. See Hills v. Gautreaux, 425 U.S. 284, 293-94 (1976); Milliken v. Bradley, 418 U.S. $717,738,744-45$ (1974). Justice White has also argued that an impact approach would grant rights to individuals as members of groups which they do not have as individuals under the equal protection clause: No individual who failed a racially neutral employment test could claim a denial of his equal protection rights whatever his race. Davis, 426 U.S. at 245-46.

12. See Ely, supra note 9, at 1258-59; Kaplan, Segregation Litigation and the Schools-Part II: The General Northern Problem, 58 Nw. U.L. REv. 157, 188 (1963). But of. Eisenberg, supra note 5, at 84-85 (citing Ely, The Constitutionality of Reverse Racial Discrimination, 41 U. CHI. L. Rev. 723, 734-36 (1974)) (arguing that the costs to minorities of not considering disproportionate impact far outweigh the risks in explicitly considering race). 
pense of other legitimate social interests. ${ }^{13}$

My own sympathies lie with the critics of the doctrine of discriminatory purpose. The problems posed by a disproportionate impact standard do not seem insurmountable. ${ }^{14}$ And none of the current doctrine's proponents explain why it is important to search for bad motives or why such a search is the only alternative to an impact test. But I do not intend to simply add another chapter to the intent/impact debate. Rather, I wish to suggest another way to think about racial discrimination, a way that more accurately describes both its origins and the nature of the injury it inflicts.

Much of one's inability to know racial discrimination when one sees it results from a failure to recognize that racism is both a crime and a disease. ${ }^{15}$ This failure is compounded by a reluctance to admit that the illness of racism infects almost everyone. ${ }^{16}$ Acknowledging and understanding the malignancy are prerequisites to the discovery of an appropriate cure. But the diagnosis is difficult, because our own contamination with the very illness for which a cure is sought impairs our comprehension of the disorder.

Scholarly and judicial efforts to explain the constitutional significance of disproportionate impact and governmental motive in cases alleging racial discrimination treat these two categories as mutually exclusive. That is, while disproportionate impact may be evidence of racially discriminatory motive, ${ }^{17}$ whether impact or motive is the appropriate focus is normally posed in the alternative: Should racially disproportionate impact, standing alone, trigger a heightened level of judicial scrutiny? Or, should the judiciary apply a deferential standard to legislative and administrative decisions absent proof that the deci-

13. Brest, supra note 7, at 47-48. Brest argues that the judiciary could not administer a general doctrine disfavoring harmful results. Id. at 11 ; see also Fiss, Groups and the Equal Protection Clause, 5 PHIL. \& PUB. Aff. 107 (1976) (recognizing possible institutional limitations on the judiciary but arguing for a "group-disadvantage" equal protection test).

14. Karst and Horowitz note that many of the problems posed by the disproportionate impact test grow out of the Court's continuing adherence to a two-tiered equal protection analysis: "If the two-tier analysis was designed to soothe the Court's critics, it utterly failed to achieve its purpose. One reason for this failure is that in focusing on the standards of review, the Court gave insufficient attention to matters of substance." Karst \& Horowitz, The Bakke Opinions and Equal Protection Doctrine, 14 HaRv. C.R.-C.L. L. REv. 7, 24 (1979); see also Eisenberg, supra note 5 , at 58-75 (proposing a new equal protection test, the causation principle, under which evidence of prior race-dependent decisions that proximately caused present disparate impact would compel heightened judicial scrutiny).

15. "Immorality" and "criminality" are thought of in terms of blameworthiness. In contrast, Chester Pierce, a black psychiatrist, has described racism as a "public health problem." Pierce, Psychialric Problems of Black Minority, in 2 American Handbook of Psychiatry 512, 513 (G. Caplan 2d ed. 1974); see also Butts, whhite Racism: Its Origins, Institutions, and the Implications for Professional Practice in Mental Health, 8 INT'L J. Psychiatry 914 (1969); notes 47-54 infra and accompanying text.

16. See Lawrence, supra note 7; notes 47-54 infra and accompanying text.

17. Village of Arlington Heights v. Metropolitan Hous. Dev. Corp., 429 U.S. 252, 265 (1977); Washington v. Davis, 426 U.S. 229, 241 (1976). 
sionmakers intended a racial consequence? ${ }^{18}$ Put another way, the Court thinks of facially neutral actions as either intentionally and unconstitutionally or unintentionally and constitutionally discriminatory. ${ }^{19}$

I argue that this is a false dichotomy. Traditional notions of intent ${ }^{20}$ do not reflect the fact that decisions about racial matters are influenced in large part by factors that can be characterized as neither intentional-in the sense that certain outcomes are self-consciously soughtnor unintentional-in the sense that the outcomes are random, fortuitous, and uninfluenced by the decisionmaker's beliefs, desires, and wishes.

Americans share a common historical and cultural heritage in which racism has played and still plays a dominant role. ${ }^{21}$ Because of this shared experience, we also inevitably share many ideas, attitudes, and beliefs that attach significance to an individual's race and induce negative feelings and opinions about nonwhites. To the extent that this cultural belief system has influenced all of us, we are all racists. At the same time, most of us are unaware of our racism. We do not recognize the ways in which our cultural experience has influenced our beliefs about race or the occasions on which those beliefs affect our actions. In other words, a large part of the behavior that produces racial discrimination is influenced by unconscious racial motivation. ${ }^{22}$

There are two explanations for the unconscious nature of our racially discriminatory beliefs and ideas. First, Freudian theory states that the human mind defends itself against the discomfort of guilt by denying or refusing to recognize those ideas, wishes, and beliefs that conflict with what the individual has learned is good or right. While our histori-

18. See notes 5,9 supra.

19. See Eisenberg, supra note 5 , at 41 .

20. There is no constitutionally significant difference between intent, purpose, and motive. Id.; see also Weinzweig, supra note 5, at 305-08 (while the meaning of motive, intention, and purpose overlap, the concepts should not be conflated).

21. See D. Bell, Race, Racism and American Law (2d ed. 1980); L. Bennett, Before the Mayflower (5th ed. 1982); J. Franklin, From Slavery to Freedom (5th ed. 1980); V. Harding, There Is a River (1981); A. Higginbotham, In the Matter of Color (1978); J. Kovel, White Racism: A Psychohistory (1970); M. Marable, Black American Politics: From the Washington Marches-Jesse Jackson (1985); Delgado, Words That Wound: A Tort Action for Racial Insults, Epithets and Name-Calling, 17 HARv. C.R.-C.L. L. REv. 133, 135-43 (1982).

22. The role of the unconscious in gender discrimination is beyond the scope of this article. It should be apparent, however, that much of my analysis is applicable to unconscious sexism and the Supreme Court's use of the Davis doctrine in cases of alleged gender discrimination. See Personnel Adm'r v. Feeney, 442 U.S. 256 (1979). For a thoughtful discussion of Feeney and the intent requirement in gender discrimination cases, see Weinzweig, supra note 5, at $277-322$.

It has been argued that sexism is even more deeply imbedded in our culture than racism and, thus, less visible. See, e.g., Wasserstrom, Racism, Sexism, and Preferential Trealment: An Approach to the Topics, 24 UCLA L. REv. 581, 590 (1977). But Wasserstrom also notes that sexism is "less unequivocally regarded as unjust and unjustifiable." Id. This would indicate that until the dominant ideology wholly rejects sexism, sexist attitudes may be repressed and held at an unconscious level less often than racist attitudes. 
cal experience has made racism an integral part of our culture, our society has more recently embraced an ideal that rejects racism as immoral. When an individual experiences conflict between racist ideas and the societal ethic that condemns those ideas, the mind excludes his racism from consciousness. ${ }^{23}$

Second, the theory of cognitive psychology states that the cultureincluding, for example, the media and an individual's parents, peers, and authority figures-transmits certain beliefs and preferences. Because these beliefs are so much a part of the culture, they are not experienced as explicit lessons. Instead, they seem part of the individual's rational ordering of her perceptions of the world. ${ }^{24}$ The individual is unaware, for example, that the ubiquitous presence of a cultural stereotype has influenced her perception that blacks are lazy or unintelligent. Because racism is so deeply ingrained in our culture, it is likely to be transmitted by tacit understandings: Even if a child is not told that blacks are inferior, he learns that lesson by observing the behavior of others. These tacit understandings, because they have never been articulated, are less likely to be experienced at a conscious level.

In short, requiring proof of conscious or intentional motivation as a prerequisite to constitutional recognition that a decision is race-dependent ${ }^{25}$ ignores much of what we understand about how the human mind works. It also disregards both the irrationality of racism and the profound effect that the history of American race relations has had on the individual and collective unconscious. ${ }^{26}$

It may often be appropriate for the legal system to disregard the influence of the unconscious on individual or collective behavior. But where the goal is the eradication of invidious racial discrimination, the law must recognize racism's primary source. The equal protection clause requires the elimination of governmental decisions that take race into account without good and important reasons. Therefore, equal protection doctrine must find a way to come to grips with unconscious racism.

23. See notes 55-75 infra and accompanying text; see also Delgado, Dunn, Brown, Lee \& Hubbert, Faimess and Formality: Minimizing the Risk of Prejudice in Alternative Dispute Resolution, 1985 Wis. L. REv. 1359 (conflict between racist impulses and formal egalitarian creed a source of prejudice in adjudication).

24. See notes 76-91 infra and accompanying text.

25. See note 162 infra.

26. In using the term "collective unconscious," I refer to the collection of widely shared individual memories, beliefs, and understandings that exist in the mind at a nonreporting level. This nonreporting mental activity is widely shared because individuals who live within the same culture share common developmental experiences. This use of the term "collective unconscious" is to be distinguished from Jung's "collective unconscious," which he described as that part of the psyche that retains and transmits the common psychological inheritance of humankind. Henderson, Ancient Myths and Modern Man, in MAN AND His Symbols 104, 107 (C. Jung ed. 1964). It should also be distinguished from Freud's "archaic remnants," which Jung described as "mental forms whose presence cannot be explained by anything in the individual's own life [and] which seem to be aboriginal, innate, and inherited shapes of the human mind." Jung, Approaching the Unconscious, in MAN AND HIS Symbols, supra, at 18, 67. 
In pursuit of that goal, this article proposes a new test to trigger judicial recognition of race-based behavior. It posits a connection between unconscious racism and the existence of cultural symbols that have racial meaning. It suggests that the "cultural meaning" 27 of an allegedly racially discriminatory act is the best available analogue for, and evidence of, a collective unconscious that we cannot observe directly. This test would thus evaluate governmental conduct to determine whether it conveys a symbolic message to which the culture attaches racial significance. A finding that the culture thinks of an allegedly discriminatory governmental action in racial terms would also constitute a finding regarding the beliefs and motivations of the governmental actors: The actors are themselves part of the culture and presumably could not have acted without being influenced by racial considerations, even if they are unaware of their racist beliefs. Therefore, the court would apply strict scrutiny.

This proposal is relatively modest. It does not abandon the judicial search for unconstitutional motives, nor does it argue that all governmental action with discriminatory impact should be strictly scrutinized. Instead, it urges a more complete understanding of the nature of human motivation. While it is grounded in the Court's present focus on individual responsibility, it seeks to understand individual responsibility in light of modern insights into human personality and collective behavior. In addition, this proposal responds directly to the concern that abandoning the Washington $v$. Davis doctrine will invalidate a broad range of legitimate, race-neutral governmental actions. ${ }^{28}$ By identifying those cases where race unconsciously influences governmental action, this new test leaves untouched nonrace-dependent decisions that disproportionately burden blacks only because they are overrepresented or underrepresented among the decision's targets or beneficiaries. ${ }^{29}$

This effort to inform the discriminatory intent requirement with the learning of twentieth century psychology is important for at least three reasons. First, the present doctrine, by requiring proof that the defendant was aware of his animus against blacks, severely limits the number of individual cases in which the courts will acknowledge and remedy racial discrimination.

Second, the existing intent requirement's assignment of individualized fault or responsibility for the existence of racial discrimination distorts our perceptions about the causes of discrimination and leads us to think about racism in a way that advances the disease rather than combatting it. By insisting that a blameworthy perpetrator be found before the existence of racial discrimination can be acknowledged, the Court

27. See notes 176-296 infra and accompanying text.

28. See note 10 supra.

29. See notes 225-228 infra and accompanying text. 
creates an imaginary world where discrimination does not exist unless it was consciously intended. And by acting as if this imaginary world was real and insisting that we participate in this fantasy, the Court and the law it promulgates subtly shape our perceptions of society. ${ }^{30}$ The decision to deny relief no longer finds its basis only in raw political power or economic self-interest; it is now justifiable on moral grounds. If there is no discrimination, there is no need for a remedy; if blacks are being treated fairly yet remain at the bottom of the socioeconomic ladder, only their own inferiority can explain their subordinate position.

Finally, the intent doctrine's focus on the narrowest and most unrealistic understanding of individual fault has also engendered much of the resistance to and resentment of affirmative action programs and other race-conscious remedies for past and continuing discrimination. $^{31}$ If there can be no discrimination without an identifiable criminal, then "innocent" individuals will resent the burden of remedying an injury for which the law says they are not responsible. ${ }^{32}$ Understanding the cultural source of our racism obviates the need for fault, as traditionally conceived, without denying our collective responsibility for ra-

30. Several critical commentators have described the process by which law transmits ideological imagery that helps to preserve and legitimize existing power relationships. Those in power use the legal system to achieve results in individual legal disputes that maintain the status quo. What is less obvious, but perhaps more important, is the use of legal ideas to create and transmit utopian images that serve to justify that status quo. By representing reality in ideal terms, the law validates the socioeconomic setting in which legal decisions are made. The ideological imagery masks or denies the reality of oppressive or alienating social and economic relations and persuades us that they are fair. See, e.g., D. HAY, P. LiNEBAUGH, J. Rule, E. Thompson \& C. Winslow, Albion's Fatal Tree (1975); Delgado, The Imperial Scholar: Reflections on a Review of Civil Rights Literature, 132 U. PA. L. Rev. 561, 568-77 (1984); Freeman, supra note 3; Gabel \& Feinman, Contract Law as Ideology, in The Polrtics of LAw: A Progressive Critique 172 (D. Kairys ed. 1982); Gordon, New Developments in Legal Theory, in The Politics of Law: A Progressive Critique, supra, at 281; Kennedy, The Siructure of Blackstone's Commentaries, 28 Bufralo L. Rev. 205 (1979); Lawrence, supra note 7; Wildman, The Legitimation of Sex Discrimination: A Critical Response to Supreme Court Jurisprudence, 63 OR. L. REv. 265 (1984).

31. When the intent requirement produces a finding of no constitutional injury, this finding is generalized to mean that no actual injury has occurred. Subsequently, when raceconscious affirmative action programs are introduced, the resentment of the white individual who is displaced increases, because she has seen no injury that requires a cure. She perceives the race-conscious remedy as an unfair gift or bonus-as "reverse discrimination" favoring blacks who have been no more disadvantaged than she. See, e.g., N. Glazer, Affirmative Discrimination: Ethnic Inequality and Public Policy (1975); I. Kraft, DeFunis v. OdegaArd: Race, Merit, and the Fourteentr Amendment (1976); R. O'Neil, Discriminating AGainst Discrimination (1975). Freeman writes:

The fault concept gives rise to a complacency about one's own moral status; it creates a class of "innocents," who need not feel any personal responsibility for the conditions associated with discrimination, and who therefore feel great resentment when called upon to bear any burdens in connection with remedying violations. This resentment accounts for much of the ferocity surrounding the debate about so-called "reverse" discrimination, for being called on to bear burdens ordinarily imposed only upon the guilty involves an apparently unjustified stigmatization of those led by the fault notion to believe in their own innocence.

Freeman, supra note 3, at 1055.

32. See Delgado, supra note 30 , at 567-76; Karst, supra note 5. 
cism's eradication. We cannot be individually blamed for unconsciously harboring attitudes that are inescapable in a culture permeated with racism. And without the necessity for blame, our resistance to accepting the need and responsibility for remedy will be lessened. ${ }^{33}$

Understanding unconscious motivation will also help us comprehend and combat the hegemony of the ideology of equal opportunity. A considerable body of scholarship from the academic left has analyzed the law as a hegemonic tool of domination. ${ }^{34}$ According to one theory, domination occurs when the ruling class gains the consent of the dominated classes through a system of ideas that reinforces the morality or inevitability of the existing order. This "interest theory" sees ideology as a consciously wielded weapon, an intellectual tool that a group uses to enhance its political power by institutionalizing a particular view of reality. ${ }^{35}$

Another view of ideology draws upon the theories of unconscious motivation discussed in this article. Under this view, ideology is a defense mechanism against the anxiety felt by those who hold power through means and with motives that they cannot comfortably acknowledge. ${ }^{36}$ This "strain theory" explains ideology as a response to the strains that an individual's or a group's social role or position creates. Ideology "provides a 'symbolic outlet' for emotional disturbances generated by social disequilibrium"; 37 it enables privileged individuals to continue practices they would otherwise condemn and in which their own complicity would be painful to admit.

This understanding of ideology provides valuable insight into the seductive powers of the ideology of equal opportunity as well as into our resistance to abandoning one of its most critical conceptual images: the intent requirement. It reconciles the observation that antidiscrimination law has consistently operated not so much in the interests of blacks as in that of white elites with the seemingly conflicting experience that white men in positions of power have often acted and theo-

33. See Karst, supra note 5, at 1165-66.

34. See generally The PoLrtics of LAW, supra note 30.

35. This view is implicit in most of the leftist scholarship. See C. Geertz, Ideology As a Cullural System, in The INTERPRETATION OF Cultures 201-02 (1973).

36. Id. at 201, 203-04.

37.

"Ideology is a patterned reaction to the patterned strains of social role." It provides a "symbolic outlet" for emotional disturbances generated by social disequilibrium. And as one can assume that such disturbances are, at least in a general way, common to all or most occupants of a given role or social position, so ideological reactions to the disturbances will tend to be similar, a similarity only reinforced by the presumed commonalities in "basic personality structure" among members of a particular culture, class, or occupational category.

Id. at 204 (quoting F. Sutton, S. Harris, C. Kaysen \& J. Tobin, The American Business CREED 307-08 (1956)). 
rized with benign motives. ${ }^{38}$ Strain theory recognizes that no ideology of equal opportunity contrived through conscious manipulation can delude its purveyors as powerfully as one that arises by the process of selfmystification. The purveyors of this ideology, unlike charlatans, are themselves deluded.

This article is divided into four parts. Each part considers an anticipated challenge to my thesis and responds to that concern. The concerns are as follows: (1) What evidence is there of unconscious racism? (2) Even if unconscious racism exists, why should we recognize it in interpreting and applying the equal protection clause? (3) Given our inability to psychoanalyze individual or collective governmental decisionmakers, how do we identify unconscious racism and apply it in specific cases? (4) If we cannot hold the unconscious discriminator responsible (since he has not engaged in a blameworthy act), is there a neutral principle that justifies heightened judicial scrutiny of his political decisions?

Part I explores the relationship between the unconscious and racially discriminatory practices. ${ }^{39}$ It explains why a legal theory that seeks to remove racial prejudice from governmental decisionmaking must acknowledge and incorporate what is known about unconscious motivation. This part introduces two theoretical explanations of unconscious motivation which demonstrate our considerable, if incomplete, understanding of this phenomenon. It then considers the special case of unconscious beliefs and attitudes about race. It observes that Americans share a historical experience that has resulted in individuals within the culture ubiquitously attaching a significance to race that is irrational and often outside their awareness.

Part II examines two constitutional theories that justify the application of heightened equal protection scrutiny to governmental decisions based on race. ${ }^{40}$ Each theory posits a distinct harm that equal protection's special sensitivity to racial classifications is intended to prevent or

38. See Delgado, supra note 30, at 563-64; Lawrence, supra note 7, at 839-50. In another essay, I described the role of the unconscious in the creation of legal ideology as follows:

The ideology of equal opportunity has evolved through the collective efforts of academics writing articles, politicians making speeches, and lawyers arguing and judges deciding cases. These individuals tend to identify with the socioeconomic order in which they hold privileged positions while at the same time feeling the tension between the harsh realities of that order and their ideal images of themselves within that order. They would like to think of themselves as fair individuals who, by virtue of their hard work and superior talent, hold positions of influence in a just society. The natural response of the privileged individual confronted with this tension between the real and the ideal is to resolve it by legitimizing the existing structure to himself. This self-mystification manifests itself in his legal arguments, judicial opinions, or theoretical discussions, which in turn become part of a defense mechanism that extends beyond the individual.

Id. at 842-43; see also notes 323-327 infra and accompanying text.

39. See notes 46-111 infra and accompanying text.

40. These are the "process defect theory" and the "stigma theory." See notes 112-176 infra and accompanying text. 
eliminate. In asking whether and why the intent of the decisionmaker is important to the fulfillment of each of these rationales, one discovers that the reasons given for determining the decisionmaker's self-conscious intent are better served when unconscious motive is also taken into account.

Part III proposes a new test, the "cultural meaning" test, to trigger judicial recognition of race-based behavior. ${ }^{41}$ This part also addresses whether courts are competent to apply a test that asks them to consider the meaning of social phenomena. It notes that while the cultural meaning test may appear novel, it actually requires the courts to engage in a very ordinary kind of judicial activity, one analogous to the most basic of judicial tasks: the construction of texts. ${ }^{42}$

Part III then examines how a court might apply the cultural meaning test by exploring several cases in which the Supreme Court relied upon the intent/effect dichotomy and by discussing how this test might have made a difference in both approach and outcome. ${ }^{43}$ Both "easy" cases (where almost everyone will agree on the cultural meaning) and "hard" cases (where the cultural meaning will be controversial) are examined. I argue that the chief virtue of the cultural meaning test lies not in its ease of application but in its ability to focus our attention on the correct question: Have societal attitudes about race influenced the governmental actor's decision?

Part IV argues that there are at least two normative principles that justify judicial intervention where unconscious racial motivation has been identified. ${ }^{44}$ The first is the right to due process, which I argue is infringed by both self-conscious and unconscious racism. The second is the antidiscrimination principle, which involves interpreting "fundamental moral values that are widely shared in our society." 75 I argue that these values and the principle that embodies them should be expanded to include unconscious racism.

\section{I. “Thy Speech Maketh Thee Manifest": A Primer on the UNCONSCIOUS AND RACE}

We have found-that is we have been obliged to assume-that very powerful mental processes or ideas exist which can produce all the effects in mental life that ordinary ideas do (including effects that can in their turn become conscious as ideas), though they themselves do not become conscious. ${ }^{46}$

41. See notes 177-187 infra and accompanying text.

42. See notes 188-208 infra and accompanying text.

43. See notes 209-291 infra and accompanying text.

44. See notes 297-322 infra and accompanying text.

45. Brest, supra note 7 , at 5 .

46. S. Freud, The Ego and the Id, in 19 The Standard Edition of the Complete Psychological Works of Sigmund Freud $3 \mathrm{~J}$. Strachey ed. 1951) [hereinafter The ComPLETE WORKS]. 


\section{A. Racism: A Public Health Problem}

Not every student of the human mind has agreed with Sigmund Freud's description of the unconscious, but few today would quarrel with the assertion that there is an unconscious-that there are mental processes of which we have no awareness that affect our actions and the ideas of which we are aware. There is a considerable, and by now well respected, body of knowledge and empirical research concerning the workings of the human psyche and the unconscious. ${ }^{47}$ Common sense tells us that we all act unwittingly on occasion. We have experienced slips of the tongue and said things we fully intended not to say, 48 and we have had dreams in which we experienced such feelings as fear, desire, and anger that we did not know we had.

The law has, for the most part, refused to acknowledge what we have learned about the unconscious. Psychiatrists and psychologists are called to court to discuss the mental state of the criminal defendant or the suspected incompetent or to report on the mental pathology produced by an alleged tort, a neglectful parent, or the deprivation of a civil right. ${ }^{49}$ But in most other legal matters, students of the unconscious are excluded, and we pretend that what they have learned is unknown.

It is hardly surprising that lawyers resist recognizing theories that describe the effects of unknown forces on our lives. For the most part, this reluctance is appropriate. The law is our effort to rationalize our relationships with one another. It is a system through which we attempt to define obligations and responsibilities. Denial of the irrational is part of that system, as is our notion that one should not be held responsible for any thoughts or motives of which one is unaware. ${ }^{50}$

47. See generally L. Bourne, Psychology: Its Principles and Meanings (1985); E. EriKson, Childhood and Society (1963); H. Eysenck \& M. Eysenck, Mindwatching: Why PeoPle Behave the Way They Do (1983); A. Freud, The Ego and the Mechanisms of Defense (1946); S. Freud, The Complete Works, supra note 46; C. Jung, Psychological Reflections: An Anthology of the Writings of C.G. Jung (J. Jacobi ed. 1953); J. Katz, J. Goldstein \& A. Dershowitz, Psychoanalysis, Psychiatry, and Law (1967); T. Moore, Cognitive PSYCHOLOGY (1939).

48. J. Katz, J. Goldstein \& A. Dershowtrz, supra note 47, at 53-58.

49. See generally Girsh, Using Psychologists in the Courtroom, 35 NLADA BRIEFCASE 87 (1978); Lassen, The Psychologist as an Expert Witness in Assessing Mental Disease or Defect, 50 A.B.A. J. 239 (1964); Moore, Responsibility and the Unconscious, 53 S. CAL. L. Rev. 1563, 1639-75 (1980); Samuels, Psychiatric Evidente, 1981 CRIM. L. REv. 762.

50. In most instances, lack of conscious intent excuses the actor from the legal consequences of his act. One exception to this rule is the case where we have determined, for reasons unrelated to the actor's responsibility as an individual, that the law should always apply. But in this case, too, the law has no concern for the workings of the unconscious: The reason for applying the law is unrelated to the state of mind of the actor who occasioned its application. The law of strict liability, for example, is unconcerned with the tortfeasor's state of mind. See, e.g., Graham v. Bottenfield's Inc., 176 Kan. 68, 269 P.2d 413 (1954) (legal action can be brought against manufacturer who did not manufacture the hair dye at issue); Henningsen v. Bloomfield Motors Inc., 32 N.J. 358, 161 A.2d 69 (1960) (both manufacturer and dealer are liable for automobile malfunction); Wade, Strict Tort Liability of .Mamufacturers, 19 Sw. L.J. 5 (1965). Thus, the argument that discriminatory impact should trigger strict scrutiny 
But the body of law and legal theory that governs the application of the equal protection clause to cases of alleged racial discrimination should not blind itself to what we know about the unconscious. Racism is in large part a product of the unconscious. It is a set of beliefs whereby we irrationally attach significance to something called race. I do not mean to imply that racism does not have its origins in the rational and premeditated acts of those who sought and seek property and power. But racism in America is much more complex than either the conscious conspiracy of a power elite or the simple delusion of a few ignorant bigots. It is a part of our common historical experience and, therefore, a part of our culture. It arises from the assumptions we have learned to make about the world, ourselves, and others as well as from the patterns of our fundamental social activities.

Richard Wasserstrom has described the significance of race in our culture by contrasting our culture with a hypothetical one where race is an unimportant characteristic: "In such a culture, race would be largely if not exclusively a matter of superficial physiology; a matter, we might say, simply of the way one looked," much like eye color. ${ }^{51}$ But race does not function in our culture as does eye color, which is an irrelevant category, an unimportant cultural fact. ${ }^{52}$ Few of us can recall the color of our best friend's eyes, but when we pass a complete stranger on the street, we will remember his race. ${ }^{53}$ We attach significance to race even when we are not aware that we are doing so.

Racism is irrational in the sense that we are not fully aware of the meanings we attach to race or why we have made race significant. It is also arguably dysfunctional to the extent that its irrationality prevents the optimal use of human resources. In this light it seems an appropriate candidate for study and/or treatment by the psychoanalyst as well as for exclusion from law, the discipline that attempts to govern or influence the actions of rational people. But unlike other forms of irrational and dysfunctional behavior, which we think of as deviant or abnormal, racism is "normal." It is a malady that we all share, because we have all been scarred by a common history. Racism's universality renders it normal. 54

Racism's ubiquity underscores the importance of incorporating our knowledge of the unconscious into the legal theory of equal protection. The law has traditionally used psychological theory to define abnormality in order to exclude the irrational from the law's protection or sanc-

either implies an assertion of probable conscious but covert discriminatory intent or reasons that problems of proof, the severity of the harm, or social utility require that the burden be on the defendant without respect to his intent.

51. Wasserstrom, supra note 22 , at 585-86.

52. Id. at 586.

53. The other characteristic we will remember is sex. See note 22 supra; see also Rose, Cognitive and Dyadic Processes in Intergroup Contact, in Cognitive Process in Stereotyping and INTERGROUP BEHAVIOR 271 (L. Hamilton ed. 1981).

54. J. KoveL, supra note 21 , at 94 . 
tion. But where the law's purpose is to eradicate racial discrimination, it must recognize that racism is both irrational and normal. We must understand that our entire culture is afflicted, and we must take cognizance of psychological theory in order to frame a legal theory that can address that affliction.

\section{B. Psychoanalytic Theory: An Explanation of Racism's Irrationality}

The division of the mind into the conscious and the unconscious is the fundamental principle of psychoanalysis.55 Psychoanalytic theory explains the existence of pathological mental behavior ${ }^{56}$ as well as certain otherwise unexplained behavior in healthy people ${ }^{57}$ by postulating two powerful mental processes-the primary and the secondary-which govern how the mind works. The primary process, or Id, occurs outside of our awareness. It consists of desires, wishes, and instincts that strive for gratification. It follows its own laws, of which the supreme one is pleasure. The secondary process, or Ego, happens under conscious control and is bound by logic and reason. We use this process to adapt to reality: The Ego is required to respect the demands of reality and to conform to ethical and moral laws. On their way to gratification, the Id impulses must pass through the territory of the Ego where they are criticized, rejected, or modified, often by some defensive measure on the part of the secondary process. Defensive mechanisms such as re-

55. S. FReUd, ThE Ego AND THE ID, supra note 46 , at 3 . It is not my purpose to defend psychoanalytic theory as the definitive description of psychological processes. It has often been noted that Freud himself was constantly revising his hypothetical constructs and definitions. Rather, I have drawn upon psychoanalytic theory because it provides a conceptual vocabulary for processes that we have all observed in our everyday lives. That vocabulary, while controversial, has gathered sufficient preeminence in the scientific world and among lay persons that its meanings are understood by a relatively broad range of people. Moreover, the theory's major contribution, the discovery of motivational dynamics, is the foundation of much of modern psychology. Marie Jahoda notes that "[w] hat Churchill said about democracy can well be applied to psychoanalysis too: It is the worst theory ever proposed, except for all the others that have so far been tried." M. JAHODA, RACE RELATIONS \& MENTAL HEaLTH 11 (1960) (UNESCO publication). Mindful of the flaws in psychoanalytic theory and the diffculties it presents for empirical verification, I have also drawn heavily upon studies, concepts, and interpretations in the social sciences that are based on different theoretical premises. See notes 76-91 infra and accompanying text.

56. In his case histories, Freud explained how pathological mental behavior develops. See, e.g., S. Freud, Studies on Hysteria, in 2 The Complete Works, supra note 46, at 135 (in the case of Elisabeth von R., the patient succeeded in sparing herself the painful conviction that she loved her brother-in-law by inducing physical pains in herself); S. FREUD, Notes UPON a CASe of Obsessional Neurosis, in 10 The Complete Works, supra note 46, at 19 (in the case of the Rat Man, obsessive behavior resulted from the displacement of self-reproach related to pleasurable sexual acts performed during childhood; the patient suffered guilt and fell ill to avoid resolving the conflict).

57. For example, psychoanalytic theory explains parapraxes (i.e., "faulty acts" such as slips of the tongue or misperceptions), forgetting, and similar responses. See S. FrEUd, INTroDUCTORY LeCTURES ON PSYCHOANALYSIS, in 15 THE COMPLETE WORKS, supra note 46, at 25-79. Psychoanalysis is not only a therapy for those who suffer from mental and emotional disturbances; it is also a comprehensive general theory of personality that applies to the sick and the healthy mind alike. See generally Readings in Psychoanalytic Psychology (M. Levitt ed. 1959). 
pression, denial, introjection, projection, reaction formation, sublimation, and reversal resolve the conflicts between the primary and secondary processes by disguising forbidden wishes and making them palatable. ${ }^{58}$

Several observations about the nature of racial prejudice give credence both to the theory of repression and to the suggestion that racial antagonism finds its source in the unconscious. For example, when we say that racism is irrational, we mean that when people are asked to explain the basis of their racial antagonism they either express an instinctive, unexplained distaste at the thought of associating with the out-group as equals ${ }^{59}$ or they cite reasons that are not based on established fact and are often contradicted by personal experience. In one study on racial prejudice, E. L. Hartley included in his survey three fictitious groups he called the Dariens, the Praneans, and the Wallonians. A large portion of respondents who expressed a dislike for blacks and Jews also disliked these nonexistent groups and advocated restrictive measures against them. ${ }^{60}$

In psychoanalytic terms, this irrational behavior indicates poor "reality-testing." When people of normal intelligence behave in a way that rejects what they experience as real, it requires some explanation. Psychoanalytic theory assumes that inadequacy in reality-testing fulfills a psychological function, usually the preservation of an attitude basic to the individual's makeup. If adequate reality-testing threatens to undermine such a functionally significant attitude, it is avoided. In such cases, the dislike of out-groups is based on rationalization-that is, on socially acceptable pseudoreasons that serve to disguise the function that the antagonism serves for the individual. ${ }^{61}$

Of course, not all inadequate reality-testing is a rationalization of

58. See generally A. FrEUd, supra note 47.

59. See M. Jahoda, supra note 55, at 15 (quoting G. Carter, The Polrtics of Inequaltry, South AFrICA SINCE 1948, at 412 (1958) on the South African nationalist's horror at associating with black South Africans: "The most extreme example of this sentiment is bound up with the phrase: 'Do you want your daughter to marry a Native?" ").

60. See E. Hartley, Problems in Prejudice 21-40 (1946). Considerable research has been done on the irrationality of racism, yielding many equivalents of the notorious remark: "Some of my best friends are Jewish but ...." See, e.g., N. ACkerman \& M. JAHOda, ANTISEMTTISM AND EMOTIONAL. Disorder: A PsychoanAlytic INTERPRETATION 82-84 (1950) (antisemitism persisting notwithstanding many positive contacts with Jews); B. BETTELHEIM \& $\mathrm{M}$. Janowitz, Dynamics of Prejudice: A Psychological and Sociological Study of Veterans 33 (1950) (study of World War II veterans in the Chicago area concluded that most prejudiced people base their attitudes on untested preconceptions rather than personal experience; one veteran remarked, "There was one Jewish fellow in our outfit whom I liked especially. He wasn't like the ordinary run of Jews, that's why I remember him."); G. SELzNick \& S. Steinberg, The Tenacity of Prejudice: Antisemitism in Contemporary America (1969); Mussen, Some Personality and Social Factors Related to Changes in Children's Attitudes Toward Negroes, $45 \mathrm{~J}$. Abnormal \& Soc. Psychology 423-41 (1950) (study conducted at an interracial boys' camp concluded that getting to know members of the disliked group is not likely to change attitudes); Sanford, The Roots of Prejudice: Emotional Dynamics, in PsYchology AND RACE 57 (P. Watson ed. 1973).

61. M. JAHODA, supra note 55 , at 14 . 
hidden motives. The occasion for reality-testing is not always available, and all of us make prejudgments based on insufficient evidence. But when these prejudgments become rigidly stereotyped thinking that eschews reality even when facts are available, there is reason to search for a psychological function that the rigidity of the prejudgment fulfills. ${ }^{62}$

An examination of the beliefs that racially prejudiced people have about out-groups demonstrates their use of other mechanisms observed by both Freudian and nonFreudian behavioralists. For example, studies have found that racists hold two types of stereotyped beliefs: They believe the out-group is dirty, lazy, oversexed, and without control of their instincts (a typical accusation against blacks), ${ }^{63}$ or they believe the out-group is pushy, ambitious, conniving, and in control of business, money, and industry (a typical accusation against Jews). ${ }^{64}$ These two types of accusation correspond to two of the most common types of neurotic conflict: 65 that which arises when an individual cannot master his instinctive drives in a way that fits into rational and socially approved patterns of behavior, ${ }^{66}$ and that which arises when an

62. "Racial prejudice, in its narrowest sense, is an attitude towards outgroups which refrains from reality-testing, not just because the mental effort is too much, but because the attitude itself fulfills a specific irrational function for its bearer." Id. Scientific thought represents a major effort at rationalization-i.e., the attempt to avoid the contamination of secondary (rational) thought processes by primary (irrational) ones. Research on race questions provides numerous illustrations of the failure to achieve that goal. See, e.g., id. at 18; A. Montagu, Man's Most Dangerous Myth: The Fallacy of Race (5th ed. 1974); Snyder, On the Self-Perpetuating Nature of Social Stereotypes, in Cocnitive Processes in STEReotyping and INTERGROUP BEHAVIOR 183 (D. Hamilton ed. 1981); White, The Definition of Legal Competence: Will the Circle Be Unbroken?, 18 Santa ClaRA L. Rev. 641 (1978). Other works on the race question demonstrate that the less rational processes affect the rational processes. See, e.g., 1 G. Myrdal, An American Dilemma: The Negro Problem and Modern Democracy (1975); G. Saenger, The Social Psychology of Prejudice (1953); Bigoness, Effect of Applicant's Sex, Race, and Performance on Employers' Performance Ratings: Some Additional Findings, 61 J. AppLIED PsychologY 80 (1976).

63. See G. Allport, The Nature of Prejudice 196-98 (1954); J. Kovel, supra note 21, at 51-92; G. SElzNick \& S. STEINBERG, supra note 60, at 170-71.

64. See G. Allport, supra note 63, at 192-96; G. SElznick \& S. SteInberg, supra note 60, at 3-21.

65. See B. BetTELheim \& M. JANowitz, supra note 60 , at $156-59$ (describing case histories of antisemitic people under psychoanalytic treatment; the study found that these people projected culturally prevalent stereotypes of Jews to embody the conficts they could not face in themselves); see also M. JAHODA, supra note 55, at 28; Sofer, Working Groups in a Plural Society, 8 INDUS. \& LAB. REL. Rev. 68 (1954). A number of studies have demonstrated that this parallel between racial stereotypes and the most basic human conflicts is not fortuitous. See, e.g., T. adorno, E. Frenkel-Brunswik, D. Levinson \& R. Sanford, The Authorttarian PersonalITY 474-82 (1950) (finding that the personality type most given to intense feelings of racial prejudice is characterized by a rigid adherence to conventional values and a submissive, uncritical attitude toward idealized authorities of the in-group; to achieve some sense of identity, the authoritarian personality needs a black and white perception of the world; this need for clear-cut categories inevitably disinclines such people to look closely at their own or other people's motives; they fear that a full understanding of the world will blur the sharp divisions that tell them where they belong and who they are).

66. See T. Adorno, E. Frenkel-Brunswik, D. Levinson \& R. Sanford, supra note 65, at 474-75. Jean-Paul Sartre arrived intuitively at much the same picture as these empirical studies. See Sartre, Portrail of the Antisemile, 13 Partisan Rev. 6 (1946); see also J. Sartre, ReflexIONS SUR La Question Juive (14th ed. 1954). 
individual cannot live up to the aspirations and standards of his own conscience. ${ }^{67}$ Thus, the stereotypical view of blacks implies that their Id, the instinctive part of their psyche, dominates their Ego, the rationally oriented part. The stereotype of the Jew, on the other hand, accuses him of having an overdeveloped Ego. In this way, the racially prejudiced person projects his own conflict into the form of racial stereotypes.

The preoccupation among racially prejudiced people with sexual matters in race relations provides further evidence of this relationship between the unconscious and racism. Taboos against interracial sexual relations, myths concerning the sexual prowess of blacks, and obsessions with racial purity coexist irrationally with a tendency to break these taboos. ${ }^{68}$ Again, psychoanalytic theory provides insights: According to Freud, one's sexual identity plays a crucial role in the unending effort to come to terms with oneself. ${ }^{69}$ Thus, the prominence of racism's sexual component supports the theory that racial antagonism grows in large part out of an unstable sense of identity. ${ }^{70}$

Another piece of evidence that supports the contention that racism originates in the unconscious is the fact that racially discriminatory behavior usually improves long before corresponding attitudes toward members of the out-group begin to change. ${ }^{71}$ Again, this is to be ex-

67. Psychoanalytic theory sees conflict over one's sense of identity as universal. It results from the developmental conflict that is inevitable in the child who loves and identifies with his parents yet must be controlled, rejected, and punished by them. Before the child acquires self-control, internal standards, and the ability to understand the need for rules and regulations, this punishment and disapproval can make him feel unwanted and unloved. This conflict or lack of clarity concerning one's self-image is inescapable at one stage of development, but it may remain unresolved and become a basic feature of the adult personality. Case histories of people who feel strong racial antagonism have shown that their identity conflicts were particularly severe and remain unresolved. See M. JAHODA, supra note 55, at 18.

68. See J. Dollard, Caste and Class in a Southern Town (1937); F. Fanon, Black Skin, White Masks (1967); W. Grier \& P. CobBs, Black RAGe (1968); C. Hernton, SeX aNd Racism in AMERICa (1965); J. Kovel, supra note 21, at 25; P. Mason, The BirTh of a Dilemma (1958); A. Paton, Too late the Phalarope (1953).

69. S. Freud, Three Essays on the Theory of Sexualrty, in 7 The Complete Works, supra note 46, at 123. Psychoanalytic theory sees unresolved conflicts in one's sexual identity as the chief source of anxiety and insecurity in adulthood. See Kramer, On Discovering One's Identity, 10 Psychoanalytic Stud. Child 47 (1955); Reich, A Character Formation Representing the Integration of Unusual Confict Solutions in the Ego Structure, 13 Psychoanalytic Stud. Child 309 (1958).

70. Also note that the out-group is almost always designated by the prejudiced group as dirty or smelly or both. This parallels the psychoanalytic observation regarding the centrality of feces and dirt to developmental conflicts. See J. Kover, supra note 21, at 65-87.

71. See Cook \& Stuart, Desegregation: A Psychological Analysis, 12 Am. Psychologist 1 (1957); P. West \& M. Jahoda, Social Fictions and Social Facts (1949) (unpublished manuscript) (on file with author); see also LaPiere, Attitudes vs. Attions, 13 Soc. Forces 230 (1934) (after traveling throughout the United States with a Chinese couple, LaPiere wrote to the hotels and restaurants they had visited and asked if they would accept Chinese individuals as guests; over $90 \%$ of the respondents, all of whom had actually served the Chinese couple, said they would not); Nisbett \& Wilson, The Halo Effect: Evidence for Unconscious Alteration of Judgments, 35 J. PersonaltTy \& Soc. Psychology 250 (1977) (instructor with European accent, mannerisms, and appearance acted warm in one interview and cold in another; subjects interviewing warm instructor rated his idiosyncracies as appealing, while subjects interviewing cold instruc- 
pected in light of the underlying psychological processes. Behavior is more frequently under Ego control than is attitude. Attitude reflects, in large part, the less conscious part of the personality, a level at which change is more complex and difficult. It also seems reasonable for a change in behavior to stimulate a change in attitude, if for no other reason than that flagrant inconsistency between what one does and what one thinks is uncomfortable for most people. ${ }^{72}$

Thus far we have considered the role the unconscious plays in creating overtly racist attitudes. But how is the unconscious involved when racial prejudice is less apparent-when racial bias is hidden from the prejudiced individual as well as from others? Increasingly, as our culture has rejected racism as immoral and unproductive, this hidden prejudice has become the more prevalent form of racism. The individual's Ego must adapt to a cultural order that views overtly racist attitudes and behavior as unsophisticated, uninformed, and immoral. It must repress or disguise racist ideas when they seek expression.

Joel Kovel refers to the resulting personality type as the "aversive racist" and contrasts this type with the "dominative racist," the true bigot who openly seeks to keep blacks in a subordinate position and will resort to force to do so. ${ }^{73}$ The aversive racist believes in white superiority, but her conscience seeks to repudiate this belief or, at least, to prevent her from acting on it. She often resolves this inner conflict by not acting at all. She tries to avoid the issue by ignoring the existence of blacks, avoiding contact with them, or at most being polite, correct, and cold whenever she must deal with them. ${ }^{74}$ Aversive racists range from individuals who lapse into demonstrative racism when threatened-as when blacks get "too close"-to those who consider themselves liberals and, despite their sense of aversion to blacks (of which they are often unaware), do their best within the confines of the existing societal structure to ameliorate blacks' condition. ${ }^{75}$

tor rated them as irritating); Saenger \& Gilbert, Customer Reactions to the Integration of Negro Sales Personnel, 4 Int'l J. Opinion \& ATtrtude Res. 57 (1950) (white women who had been seen buying goods from black saleswomen denied that they would do so).

72. See M. JAHODA, supra note 55 , at 43 .

73. J. KovEL, supra note 21 , at 54-55. Kovel sees the decline of dominative racism and the ascent of aversive racism as products of the rationalization of the industrial state. $\mathrm{He}$ argues that the state has attacked dominative racism because it has become more threatening than useful as a regulator of culture. The industrial nation-state can no longer afford the disruption of dominative racism. See also D. BELL, supra note 21, at 437-44 (arguing that legally sanctioned segregation no longer furthers and, in fact, now harms the interests of those whites who make policy for the country); Klare, The Quest for Industrial Democracy and the Struggle Against Racism: Perspectives from Labor Law and Civil Rights Law, 61 OR. L. Rev. 157 (1982) (arguing that legal ideas about workers' rights and racial equality legitimate and reinforce a view of justice that is hospitable to domination and inequality).

74. J. Kovel, supra note 21, at 54-55.

75.

The self of the aversive racist is realized as a more socially coherent system within bourgeois culture, and such articulation may result in exceedingly principled activity. The aversive racist may behave in the most apparently constructive way, even to the 
There is considerably less research and literature concerning the aversive racist than there is concerning the self-conscious racist. This is hardly surprising. Our culture has only recently rejected the morality of white supremacy; the repression of racist ideas is a relatively new phenomenon. It is also a more difficult phenomenon to discern and observe than is self-conscious racism. The researcher's subjects no longer readily admit their membership in the group to be studied. Also, those who would observe and document unconscious racism are not themselves immune from its blight.

\section{A Cognitive Approach to Unconscious Racism}

Cognitive psychologists offer a contrasting model for understanding the origin and unconscious nature of racial prejudice. ${ }^{76}$ This is essentially a rational model. The cognitivists acknowledge the importance of emotional and motivational factors, but they do not embrace the Freudian belief that instinctive drives dominate individuals' concepts, attitudes, and beliefs. Instead, they view human behavior, including racial prejudice, as growing out of the individual's attempt to understand his relationship with the world (in this case, relations between groups) while at the same time preserving his personal integrity. But while the ultimate goal of the cognitive process is understanding or rationality, many of the critical elements of the process occur outside of the individual's awareness. ${ }^{77}$ This is especially true when there is tension be-

extent of giving money and support to the cause of bettering the lives of Negroes, yet retain the characteristic aversion ....

... As a consequence, the active entertainment of race fantasies is suppressed.

The fantasies become weaker, neutral; they are sublimated. The sublimation takes the form of a general rationalization of the personality, a diffuse coolness in sensibility and functioning. The aversion toward black people becomes but an aspect of the general personality change.

Id. at 60-61.

76. See generally M. Goodman, Race Awareness in Young Children (1952); G. Saenger, supra note 62; Nisbett \& Wilson, Telling More than We Can Know: Verbal Reports on Mental Processes, 84 Psychological Rev. 231 (1977); Snyder, supra note 62; Tajfel, Cognitive Aspects of Prejudice, 25:4 J. Soc. Issues 79 (1969).

Other students of human behavior, particularly developmental and social psychologists, have offered other explanations for the origins and mechanisms of racist behavior. One school of thought explains the development of racial awareness and prejudice as a pattern of behavior acquired by mimicking role models, especially parents, at a very young age. Psychologists who have studied racial awareness and stereotypes in young children have noted that while children are aware of the sources of these attitudes, they tend to forget the ideas' origins toward adolescence. Pushkin \& Veness, The Development of Racial Awareness and Prejudice in Children, in Psychology AND RACE, supra note 60, at 23, 37. These studies also indicate that parents frequently fail to remember giving race-preferential instructions to their children and that many parents who give lip service to ideas of tolerance continue to convey prejudiced attitudes to their children. Id; see also notes 65-66 supra and accompanying text (racism and ethnocentric attitudes develop as part of a more general personality type called the "authoritarian personality").

77. Cognitive psychologists describe the development of attitudes concerning race as the result of three fundamental psychological processes: categorization, assimilation, and the search for coherence. See, e.g., Tajfel, supra note 76, at 79-97; see also notes 79-91 infra and accompanying text. 
tween the individual's desire for simplification and the complexity of the real world or conflict between an understanding of a situation that preserves the individual's self-image and one that jeopardizes a positive view of himself. 78

Cognitivists see the process of "categorization" as one common source of racial and other stereotypes. All humans tend to categorize in order to make sense of experience. Too many events occur daily for us to deal successfully with each one on an individual basis; we must categorize in order to cope. ${ }^{79}$ When a category-for example, the category of black person or white person-correlates with a continuous dimension-for example, the range of human intelligence or the propensity to violence-there is a tendency to exaggerate the differences between categories on that dimension and to minimize the differences within each category. ${ }^{80}$

The more important a particular classification of people into groups is to an individual, the more likely she is to distinguish sharply the characteristics of people who belong to the different groups. ${ }^{81}$ Here, cognitivists integrate the observations of personality theorists and social psychologists with their own. If an individual is hostile toward a group of people, she has an emotional investment in preserving the differentiations between her own group and the "others." 82 Thus, the preservation of inaccurate judgments about the out-group is self-rewarding. ${ }^{83}$ This is particularly so when prejudiced judgments are made in a social context that accepts and encourages negative attitudes toward the outgroup. In these cases, the group judgment reinforces and helps maintain the individual judgment about the out-group's lack of worth.

The content of the social categories to which people are assigned is generated over a long period of time within a culture and transmitted to individual members of society by a process cognitivists call "assimilation." Assimilation entails learning and internalizing preferences and evaluations. ${ }^{84}$ Individuals learn cultural attitudes and beliefs about

78. Tajfel, supra note 76 , at 80 .

79. "In a rather formal way, the problem of stereotypes is that of the relation between a set of attributes which vary on continuous dimensions and classifications which are discontinuous." Id. at 82; see also G. AllPORT, supra note 63, at 19 (categories, including ethnic categories, used to simplify experience); Tajfel, Quantitative Judgment in Social Perception, 50 BrIT. J. Psycholocy 16, 16-29 (1959) (values attached to ethnic categories skew perception).

80. For example, when subjects were asked to estimate the length of randomly presented lines, they exaggerated the differences between a group of four shorter lines that were labeled $A$ and four longer lines that were labeled $B$. Their judgments were considerably more accurate when the lines were presented to them without labels. Tajfel, The Roots of Prejudice: Cognitive Aspects, in Psychology and RACE, supra note 60, at 76. As is apparent from this experiment, the tendency to stereotype categories occurs outside of the subject's awareness, and it occurs even when the objects of categorization lack any social or emotional relevance.

81. Tajfel, supra note 79, at 25.

82. Tajfel, supra note 76 , at $83-85$.

83. Id. at 86 .

84. By "internalizing" I mean that one not only learns the preferences but, at the same time, makes them one's own. 
race very early in life, at a time when it is difficult to separate the perceptions of one's teacher (usually a parent) from one's own. In other words, one learns about race at a time when one is highly sensitive to the social contexts in which one lives. ${ }^{85}$

Piaget, in his work on the development of moral judgment in children, described the transition from the stage when children judge pronouncements by their source rather than their content to the stage when children begin to cooperate with equals and to take the role of the other. This ability to see the same data from more than one point of view is the basis of intellectual and moral development. According to Piaget, this transition cannot take place when a child is exposed to only one source of information. ${ }^{86}$ These pretransition conditions, when the child remains in awe of the source of truth, tend to be precisely the conditions under which children learn socially sanctioned truths about race. Lessons learned at this early developmental stage are not questioned: They are learned as facts rather than as points of view. 87

Furthermore, because children learn lessons about race at this early stage, most of the lessons are tacit rather than explicit. Children learn not so much through an intellectual understanding of what their parents tell them about race as through an emotional identification with who their parents are and what they see and feel their parents do. Small children will adopt their parents' beliefs because they experience them as their own. If we do learn lessons about race in this way, we are not likely to be aware that the lessons have even taken place. ${ }^{88}$ If we are unaware that we have been taught to be afraid of blacks or to think of them as lazy or stupid, then we may not be conscious of our internalization of those feelings and beliefs.

All of these processes, most of which occur outside the actor's consciousness, are mutually reinforcing. Furthermore, there is little in our environment to counteract them; indeed, our culture often supports and rewards individuals for making hostile misjudgments that exaggerate the differences between themselves and members of a racial outgroup. Cultural prejudice also removes the possibility of checking judgments against outside reality, further inhibiting the chance that the holder of a prejudiced belief will perceive his mistake and correct it. Thus, through personal and cultural experience the individual comes to associate characteristics such as "intelligence," "laziness," "honesty,"

85. M. Goodman, supra note 76, at 36-60; Tajfel, supra note 76, at 88-89. See generally K. Clark, Prejudice and Your ChILd (2d ed. 1963) (constructive ways for parents to teach their children about race discrimination).

86. Holmes, Freud, Piaget and Democratic Leadership, 16 BrIT. J. Soc. 123, 135 (1965).

87. Tajfel, supra note 76 , at 87 .

88. In a study of racial awareness among nursery school children between the ages of three-and-one-half and five-and-one-half, psychologist Mary Goodman found that parents of children who expressed hostile attitudes toward blacks had no memory of having taught their children these attitudes. M. Goodman, supra note 76, at 110-18. 
or "dirtiness" with classifications of people.89 In ambiguous social situations, it will always be easier to find evidence supporting an individual's assumed group characteristics than to find contradictory evidence. Furthermore, whenever one is confronted with the need to interpret the behavior of members of a particular group en masse, there will be little opportunity to observe behavior that conflicts with the group's assumed characteristics. ${ }^{90}$

Case studies have demonstrated that an individual who holds stereotyped beliefs about a "target" will remember and interpret past events in the target's life history in ways that bolster and support his stereotyped beliefs and will perceive the target's actual behavior as reconfirming and validating the stereotyped beliefs. ${ }^{91}$ While the individual may be aware of the selectively perceived facts that support his categorization or simplified understanding, he will not be aware of the process that has caused him to deselect the facts that do not conform with his rationalization. Thus, racially prejudiced behavior that is actually the product of learned cultural preferences is experienced as a reflection of rational deduction from objective observation, which is nonprejudicial behavior. The decisionmaker who is unaware of the selective perception that has produced her stereotype will not view it as a stereotype. She will believe that her actions are motivated not by racial prejudice but by her attraction or aversion to the attributes she has "observed" in the groups she has favored or disfavored.

\section{Unconscious Racism in Everyday Life}

Whatever our preferred theoretical analysis, there is considerable commonsense evidence from our everyday experience to confirm that we all harbor prejudiced attitudes that are kept from our consciousness.

When, for example, a well-known sports broadcaster is carried away by the excitement of a brilliant play by an Afro-American professional football player and refers to the player as a "little monkey" during a nationally televised broadcast, 92 we have witnessed the prototypical

89. These subjective associations are, for the most part, socially based; the culture's history generates their content. See notes 178-187 infra and accompanying text.

90. Tajfel, supra note 76 , at 83 .

91. See, e.g., Snyder, supra note 62 , at $187-90$ (reporting a study in which participants were read narratives about the life history of a woman; one week later, some learned she was homosexual and others learned she was heterosexual; each varied his interpretation of her life history to accommodate the new piece of information; Snyder refers to this as "preferential remembering in the reconstructive process").

A stereotype is used as a guideline; where gaps are left, an individual will fill them in with the stereotyped beliefs. Also, the guidelines are used to interpret remembered events in ways that enhance their congruence with the stereotype. Id. at 190-92. Cognitive bolstering processes may be prospective and exert before-the-fact influences on the acquisition and interpretation of information learned later about the target; or, they may be retrospective and exert after-the-fact influences on the remembering and reinterpretation of previously learned information about the target. The reality is a subjective one and social stereotypes can and do create their own social reality. Id. at 193.

92. Shapiro, Cosell's Remark Raises Ire, Wash. Post, Sept. 6, 1983, at D6, col. 1. 
parapraxes, or unintentional slip of the tongue. This sportscaster views himself as progressive on issues of race. Many of his most important professional associates are black, and he would no doubt profess that more than a few are close friends. ${ }^{93}$ After the incident, he initially claimed no memory of it and then, when confronted with videotaped evidence, apologized and said that no racial slur was intended. ${ }^{94}$ There is no reason to doubt the sincerity of his assertion. Why would he intentionally risk antagonizing his audience and damaging his reputation and career? But his inadvertent slip of the tongue was not random. ${ }^{95}$ It is evidence of the continuing presence of a derogatory racial stereotype that he has repressed from consciousness and that has momentarily slipped past his Ego's censors. ${ }^{96}$ Likewise, when Nancy Reagan appeared before a public gathering of then-presidential-candidate Ronald Reagan's political supporters and said that she wished he could be there to "see all these beautiful white people,"97 one can hardly imagine that it was her self-conscious intent to proclaim publicly her preference for the company of Caucasians.

Incidents of this kind are not uncommon, even if only the miscues of the powerful and famous are likely to come to the attention of the press. ${ }^{98}$ But because the unconscious also influences selective perceptions, ${ }^{99}$ whites are unlikely to hear many of the inadvertent racial slights

93. Howard Cosell was the first white reporter to respect Muhammad Ali's wish to be called by his Muslim, rather than his Christian, name; it was the resulting relationship with Ali that brought Cosell to prominence. Cf. id. (quoting Cosell as saying, "Where were they when I fought for Muhammad Ali's rights?").

94. "No man respects Alvin Garrett more than I do. I talked about that man's ability to be so elusive despite the smallness of his size." Id.

95. Why, for instance, did Cosell use the word "monkey," an animal long associated with caricatures and stereotypes of blacks, rather than "rabbit" or "deer" or "jet"?

96. In his Introductory Lectures on Psychoanalysis, Freud pointed out that the most common parapraxes are slips of the tongue in which one says the precise opposite of what one intended to say. S. FREUD, supra note 57, at 33. These parapraxes do have a sense of their own. "[P]arapraxes are the outcome of a compromise: They constitute a half-success and a halffailure for each of the two intentions; the intention which is being challenged is neither completely suppressed nor, apart from special cases, carried through quite unscathed." Id. at 66 .

97. Mrs. Reagan made the comment at a reception in Chicago. The manager of Reagan's Illinois campaign defended Mrs. Reagan by pointing out that "she was talking to her husband about the white snow and that's how she got mixed up." Wash. Post, Feb. 18, 1980, at A2, col. 1; see also R. Dugcer, On Reagan: The Man and His Presidency 202 (1983).

98. See Coast Police Chief Accused of Racism, N.Y. Times, May 13, 1982, at A24, col. 1 (remark of Los Angeles police chief that some blacks might be more susceptible than "normal" people to injury when officers applied a choke hold); Notes on People, N.Y. Times, Dec. 3, 1977, at 21, col. 3 (Lieutenant Governor Lowell Thomas, Jr. of Alaska apologized for his comment that racial intermarriage was "against nature"); see also Remnick, Blunders that Rebound on ('s All, Wash. Post, Dec. 26, 1983, at B2, col. 4 (racist remarks by sportscasters: First is Tom Brookshier's comment that the University of Louisville players (all black) have a collective IQ of about 40, though they can play basketball; the second remark was Howard Cosell's, see note 92 supra; the third and fourth blunders were made by Rick Barry, "[r]emarking on Bill Russell's 'watermelon smile' and 'joking' that the green ribbons worn by the Boston Celtics in memory of the black children murdered in Atlanta were in honor of St. Patrick's Day").

99. For a discussion of the phenomenon of selective perception, see R.L. Atrinson, R.C. AtKinson \& E. Hilgard, Introduction to Psychology 146-50 (8th ed. 1983); J. Coleman, Psychology and Effective Behavior 168-70 (1969); L. Crow \& A. Crow, Under- 
that are made daily in their presence. ${ }^{100}$

Another manifestation of unconscious racism is akin to the slip of the tongue. One might call it a slip of the mind: While one says what one intends, one fails to grasp the racist implications of one's benignly motivated words or behavior. For example, in the late 1950s and early $1960 \mathrm{~s}$, when integration and assimilation were unquestioned ideals among those who consciously rejected the ideology of racism, white liberals often expressed their acceptance of and friendship with blacks by telling them that they "did not think of them as Negroes." Their conscious intent was complimentary. The speaker was saying, "I think of you as normal human beings, just like me." But he was not conscious of the underlying implication of his words. What did this mean about most Negroes? Were they not normal human beings? If the white liberal were asked if this was his inference, he would doubtless have protested that his words were being misconstrued and that he only intended to state that he did not think of anyone in racial terms. But to say that one does not think of a Negro as a Negro is to say that one thinks of him as something else. The statement is made in the context of the real world, and implicit in it is a comparison to some norm. In this case the norm is whiteness. ${ }^{101}$ The white liberal's unconscious thought, his slip of the mind, is, "I think of you as different from other Negroes, as more like white people."

One indication of the nonneutrality of the statement, "I don't think of you as a Negro," when spoken as a compliment by a white is the incongruity of the response, "I don't think of you as white." This could also be a complimentary remark coming from a black, conveying the fact that she does not think of her friend in the usual negative terms she

standing Our Behavior: The Psychology of Personal and Social Adjustment 90-180 (1956); E. Erb \& D. Hooker, The Psychology of the Emerging Self: AN Integrated INterpretation of Goal-Directed Behavior 187-214 (1967). See generally H. Bernard \& W. Huckins, Dynamics of Personal Adjustment (1971) (development of concepts of oneself and others during childhood and adolescence); H. EysEnCK \& M. EYSENCK, supra note 47 (general discussion of personality development).

100. It is common for racial minorities, especially those who find themselves relatively isolated in predominantly white institutions, to have white colleagues express stereotyped or derogatory views either by way of direct statements or by unstated but implicit assumptions. The most common examples of this are being mistaken for another black or Asian who looks nothing like you (the "they all look alike" syndrome), see Alleyne, "They All Look Alike" is No Joke in Court, L.A. Times, Apr. 15, 1984, pt. VI, at 5, col. 3, or the assumption that a black can dance and sing and grew up in the ghetto. It is obvious to the minority person that the speaker has not intended a racial slight-his tone is friendly and candid-and that he is unaware of the attitudinal source of the inadvertent derogation. And when other whites are present, they are unlikely to hear or be sensitive to the connotations of the demeaning remark.

101. One of my former students-a Mexican-American woman, a Harvard graduate, and a third-year law student at Stanford-was complimented on her verbal proficiency by a middle-aged white male who was interviewing her for a job with his law firm. "You speak very good English," he said. His statement was obviously intended as a compliment. "My family has lived in Santa Barbara for four generations," replied the student. The interviewer was unconscious of the racial stereotype underlying his intended compliment-that of the poor, uneducated immigrant. The student heard only that stereotype. "Of course I speak English well," she thought, but she was careful not to say, "Haven't you read my resume?" 
associates with whiteness. But this statement does not make sense coming from an individual who would accept as complimentary a statement characterizing her as unlike other Negroes. If anything, the response only makes sense as a lighthearted but cautionary retort. It conveys the following message: "I understand that your conscious intent was benign. But let me tell you something, friend. I think being black is just fine. If anything, our friendship is possible because you are unlike most white folks."

Of course, the statements of both these interlocutors are ethnocentric. But it is the white who has made the slip of the mind. He was unmindful of the ethnocentric premise upon which his "compliment" was based. He would find it painful to know that it is a premise in which he believes. His black friend's ethnocentrism is self-conscious and self-affirming. She is well aware of the impact of her reply. It is a defensive parry against the dominant society's racism.

Richard Wasserstrom has called this failure to see the implicit racism in a racially neutral line of reasoning "conceptual racism." $102 \mathrm{He}$ gives as an example the Supreme Court's reasoning in Brown $I I^{103}$ in ordering school integration to proceed not immediately but "with all deliberate speed." 104 The Court said that there were "complexities arising from the transition to a system of public education freed from racial discrimination" 105 which would require time to resolve. ${ }^{106}$

Wasserstrom calls this reasoning "a fantastic bit of nonsense."107 He notes that the chief difficulty with immediate enforcement of Brown I was not the technical problems to which the Court referred but the resistance of whites theretofore in an unconstitutionally privileged position. The Court's reference to the technical problems of change may well have been a conscious rationalization for the sake of political expe-

102.

We have a variety of ways of thinking about the legal system, and we have a variety of ways of thinking within the legal system about certain problems. We use concepts. Quite often without realizing it, the concepts used take for granted certain objectionable aspects of racist ideology without our being aware of it.

Wasserstrom, supra note 22, at 599.

103. Brown v. Board of Educ., 349 U.S. 294 (1955) ("Brown IF"). There was a second Brown case, because, having found racially segregated schools unconstitutional in Brown v. Board of Educ., 347 U.S. 483 (1954) ("Brown $I$ "), the Court, rather than follow the usual practice of ordering that the invalid practice cease immediately, treated relief as a distinct question to be decided separately. Id. at 495-96.

104. Brown II, 349 U.S. at 301.

105. Id. at 299.

106. More specifically, the Court indicated that time might be necessary to carry out the ruling because of:

problems related to administration, arising from the physical condition of the school plant, the school transportation system, personnel, revision of school districts and attendance areas into compact units to achieve a system of determining admission to the public schools on a nonracial basis, and revision of local laws and regulations which may be necessary in solving the foregoing problems.

Id. at 300-01.

107. Wasserstrom, supra note 22 , at 600 . 
diency, ${ }^{108}$ but Wasserstrom suggests that it may also have involved unconscious racism: The Justices may have relied on some assumptions that were significant in the dominant racist ideology. They may have tacitly reasoned that the black schools were wretched, that white children could not attend those schools, and thus, while it was unfair to deprive blacks by making them go to inferior segregated schools, they would have to wait until the black schools were either eliminated or sufficiently improved for everybody to attend. 109

A crucial factor in the process that produces unconscious racism is the tacitly transmitted cultural stereotype. If an individual has never known a black doctor or lawyer or is exposed to blacks only through a mass media where they are portrayed in the stereotyped roles of comedian, criminal, musician, or athlete, he is likely to deduce that blacks as a group are naturally inclined toward certain behavior and unfit for certain roles. ${ }^{110}$ But the lesson is not explicit: It is learned, internalized, and used without an awareness of its source. Thus, an individual may select a white job applicant over an equally qualified black and honestly believe that this decision was based on observed intangibles unrelated to race. The employer perceives the white candidate as "more articulate," "more collegial," "more thoughtful," or "more charismatic." $\mathrm{He}$ is unaware of the learned stereotype that influenced his decision. Moreover, he has probably also learned an explicit lesson of which he is very much aware: Good, law-abiding people do not judge others on the basis of race. Even the most thorough investigation of conscious motive will not uncover the race-based stereotype that has influenced his decision.

This same process operates in the case of more far-reaching policy decisions that come to judicial attention because of their discriminatory impact. For example, when an employer or academic administrator discovers that a written examination rejects blacks at a disproportionate rate, she can draw several possible conclusions: that blacks are less qualified than others; that the test is an inaccurate measure of ability; or that the testers have chosen the wrong skills or attributes to measure. ${ }^{11}$ When decisionmakers reach the first conclusion, a predisposition to select those data that conform with a racial stereotype may well have influenced them. Because this stereotype has been tacitly transmitted and unconsciously learned, they will be unaware of its influence on their decision.

If the purpose of the law's search for racial animus or discriminatory intent is to identify a morally culpable perpetrator, the existing intent requirement fails to achieve that purpose. There will be no evidence of

108. See Steel, A Critic's View of the Warren Court-Nine Men in Black Who Think White, N.Y.

Times, Oct. 13, 1968, $\S 6$ (Magazine), at 56.

109. Wasserstrom, supra note 22 , at 600 .

110. See notes 252-253 infra and accompanying text.

111. See notes $276-278$ infra and accompanying text. 
self-conscious racism where the actors have internalized the relatively new American cultural morality which holds racism wrong or have learned racist attitudes and beliefs through tacit rather than explicit lessons. The actor himself will be unaware that his actions, or the racially neutral feelings and ideas that accompany them, have racist origins.

Of course, one can argue that the law should govern only consciously motivated actions-that societal sanctions can do no more than attempt to require that the individual's Ego act as society's agent in censoring out those unconscious drives that society has defined as immoral. Under this view, the law can sanction a defective Ego that has not fully internalized current societal morality and has, therefore, allowed illegal racist wishes to reach consciousness and fruition in an illegal act. But the law should not hold an individual responsible for wishes that never reach consciousness, even if they also come to fruition in discriminatory acts.

The problem is that this argument does not tell us why the law should hold the individual responsible for racial injury that results from one form of Ego disguise but not the other. I believe the law should be equally concerned when the mind's censor successfully disguises a socially repugnant wish like racism if that motive produces behavior that has a discriminatory result as injurious as if it flowed from a consciously held motive.

\section{A TALE of Two Theories}

The second likely challenge to my proposal acknowledges the existence of unconscious racism but questions whether it is important or even useful to take it into account in interpreting and applying the equal protection clause. This question can best be answered by posing a more general question: What is the wrong that the equal protection clause seeks to address? More specifically, what wrong do we seek to address in applying heightened scrutiny to racial classifications? If we can determine the nature of this wrong, we can determine whether identifying the existence of unconscious racial motivation is important to its prevention or remediation.

Two theories have attempted to specify the central function of suspect classification doctrine. ${ }^{112}$ The first, the "process defect" theory, sees the judicial intervention occasioned by strict scrutiny of suspect

112. I refer here to substantive, as opposed to structural, theories of equal protection. The Supreme Court has avoided articulating any substantive content of the equal protection clause. See note 299 infra. Instead, it relies heavily on a structural approach that Tussman and tenBroek first described, see Tussman \& tenBroek, The Equal Protection of the Lawe, 37 Calif. L. REv. 341 (1949), and that Gerald Gunther further elaborated, see Gunther, Foreword: In Search of Evalving Doctrine on a Changing Court: $A$ Model for a Newer Equal Protection, 86 HARv. L. Rev. 1 (1972); see also Freeman, supra note 3, at 1058-59 (asserting that this approach implicitly depends on value choices); Karst \& Horowitz, supra note 14, at 23-24 (noting that the Court's structural approach is inadequate because it fails to articulate clearly the substantive meaning of equal protection). 
classifications as an appropriate response to distortions in the democratic process. ${ }^{113}$ The second theory cites racial stigma as the primary target of suspect classification doctrine. ${ }^{114}$ By examining whether and why the determination of self-conscious motive is important to each of these theories, we will be able to determine whether recognizing the presence of unconscious motive furthers the central rationale of each theory. ${ }^{115}$

\section{A. The Process Defect Theory}

The chief proponent of the process defect theory has been John Ely. ${ }^{116}$ He identifies the systematic exclusion of a group from the normal workings of the political process as the harm that heightened judicial scrutiny for suspect classifications seeks to prevent or remedy. The theory begins with Justice Stone's Carolene Products footnote four, ${ }^{117}$ which states that "discrete and insular" minorities deserve special constitutional protection. Ely notes that if "minority" referred solely to the fact that the group in question was on the losing side of a particular political battle, or if "discrete and insular" referred only to its position on the wrong side of the statutory line and its inability to gather enough allies to defeat legislation, then Stone's category would be indeterminate. ${ }^{118}$ Justice Stone's reference, argues Ely, was rather to "the sort of 'pluralist' wheeling and dealing" by which minorities in our society typically interact to protect their interests: It denotes those minorities for which " 'mutual defense pacts' will prove recurrently unavailing." 119

The general idea of this theory is clear enough: Courts should protect those who cannot protect themselves politically. What Ely has

113. See notes 116-140 infra and accompanying text. Justice Stone first articulated this theory in his famous footnote four to United States v. Carolene Prods. Co., 304 U.S. 144, 152 n.4 (1938).

114. See notes 141-175 infra and accompanying text. Justices Brennan and Marshall have been the Court's chief proponents of this theory. See, e.g., City of Memphis v. Greene, 451 U.S. 100, 135 (1981) (Marshall, J., dissenting); Regents of Univ. of Cal. v. Bakke, 438 U.S. 265, 324 (1978) (Brennan, J., concurring in part and dissenting in part).

115. A third substantive theory of equal protection suggests that racial groups should be treated as moral entities with group rights to distributive and compensatory justice. It holds that it is prima facie unjust for one racial or ethnic group to be substantially worse off than another. This "group disadvantaging principle" requires relief for any group that constitutes a "perpetual underclass" and argues that such redistribution would express an ethical view disfavoring caste. See Fiss, supra note 13, at 150-51. This article will not discuss this approach. Fiss' theory is essentially indifferent to the motives and history that have led to unequal distribution and is, therefore, sufficiently sensitive to the correction of disadvantage resulting from unconscious racism without the assistance of my analysis.

116. See J. Ely, Democracy and Distrust 135-79 (1980); Ely, The Constitutionality of Reverse Racial Discrimination, 41 U. CHI. L. Rev. 723 (1974); Ely, The Wages of Crying Wolf: A Comment on Roe v. Wade, 82 YaLE L.J. 920, 933 (1973) [hereinafter Ely, Crying IWolf]; Ely, supra note 9 , at $1228-30,1254-60$.

117. Carolene Prods., 304 U.S. at 152 n.4.

118. J. ELY, supra note 116 , at 151 .

119. Id. 
added to Justice Stone's hypothesis is an explanation for why the Court should interfere with a political majority's normally legitimate choices in some instances and not in others. It invokes special scrutiny when the minority in question is one that keeps finding itself on the wrong end of legislative classifications because of the distorting effect of prejudice on the judgment of political decisionmakers. ${ }^{120}$

Ely notes that prejudice distorts the political process in two ways: First, it bars groups that are the objects of widespread vilification from the "pluralists' bazaar" that Madison believed would allow groups with overlapping interests to create majorities on given issues. The adverse reaction to the vilified minority prevents groups from recognizing and acting upon common interests that would otherwise lead them to form coalitions with the minority on certain issues. ${ }^{121}$ Second, prejudice causes the governmental decisionmakers to misapprehend the costs and benefits of their actions, ${ }^{122}$ because they seize upon positive myths about the group to which they belong and negative myths about those groups to which they do not. ${ }^{123}$ The first defect keeps the political process from giving certain minorities in our nation of minorities a chance to protect themselves within that process. The second defect prevents those who have gained control of the process from rationally and accurately assessing the most efficacious means of achieving even constitutionally legitimate goals.

Motive and intent are at the center of Ely's theory. The function of suspect classification doctrine is to expose unconstitutional motives that may have distorted the process. ${ }^{124}$ A statute that classifies by race is strictly scrutinized, because the requirement of "close fit" between end sought and means used will reveal those instances where the actual motive of the legislature was to disadvantage a group simply because of

120.

[P]rejudice is a lens that distorts reality. We are a nation of minorities and our system thus depends on the ability and willingness of various groups to apprehend those overlapping interests that can bind them into a majority on a given issue; prejudice blinds us to overlapping interests that in fact exist.... "Race prejudice divides groups that have much in common (blacks and poor whites) and unites groups (white, rich and poor) that have little else in common than their antagonism for the racial minority. Race prejudice, in short, provides the 'majority of the whole' with that 'common motive to invade the rights of other citizens' that Madison believed improbable in a pluralistic society."

Id. at 153 (quoting Goodman, supra note 10 , at 315 ).

121. See note 120 supra and accompanying text.

122. J. ELY, supra note 116 , at 153-58.

123. Id. at $158-60$.

It is inconsistent with constitutional norms to select people for unusual deprivation on the basis of race, religion, or politics, or even simply because the official doing the choosing doesn't like them. When such a principle of selection has been employed, the system has malfunctioned: indeed we can accurately label such a selection a denial of due process.

Id. at 137 (footnote omitted); see also Ely, Crying IVolf, supra note 116.

124. J. ELY, supra note 116 , at 146, 153; see also note 9 supra. 
its race. ${ }^{125}$

Under present doctrine, the courts look for Ely's process defect only when the racial classification appears on the face of the statute or when self-conscious racial intent has been proved under the Davis test. ${ }^{126}$ But the same process distortions will occur even when the racial prejudice is less apparent. Other groups in the body politic may avoid coalition with blacks without a conscious awareness of their aversion to blacks or of their association of certain characteristics with blacks. They may take stands on issues without realizing that their reasons are, in part, racially oriented. Likewise, the governmental decisionmaker may be unaware that she has devalued the cost of a chosen path, because a group with which she does not identify will bear that cost. Indeed, because of her lack of empathy with the group, she may have never even thought of the cost at all.

Process distortion exists where the unconstitutional motive of racial prejudice has influenced the decision. It matters not that the decisionmaker's motive may lie outside her awareness. For example, in Village of Arlington Heights v. Metropolitan Housing Development Corp., ${ }^{127}$ a predominantly white, upper middle class Chicago suburb prevented the construction of a proposed housing development for low and moderate income families by refusing to rezone the projected site to allow multifamily units. The Supreme Court agreed that the decision not to rezone had racially discriminatory effects, ${ }^{128}$ but it rejected the black plaintiffs' equal protection claim on the ground that they had "simply failed to carry their burden of proving that discriminatory purpose was a motivating factor in the Village's decision." 129 The Court focused on the lack of any evidence of conscious intent to discriminate on the part of either the city council in enacting the zoning ordinance that restricted use to single family homes or the planning commission in administering the ordinance. ${ }^{130}$

125. J. ELY, supra note 116 , at $145-48$.

126. Ely has limited his analysis to demonstrating that suspect classification doctrine functions "as a handmaiden of motivation analysis": He shows that when it is impossible to confidently demonstrate unconstitutional motive, a suspect classification will face serious constitutional difficulty because of the close fit required by strict scrutiny. Obviously, a legislature cannot invoke an unconstitutional goal in a statute's defense. Thus, where the legislature's real goal was unconstitutional, it will probably not be able to invoke the goal that fits the classification best; the classification will have to be defended in terms of other goals to which it relates more tenuously. Id. at $145-46$.

But Davis requires that the plaintiff prove an unconstitutional motive in order to establish the presence of a suspect classification. This renders Ely's analysis useless where the suspect classification is not apparent on the face of the statute or governmental action. This is the usual case, because the governmental actor who is attempting to disguise unconstitutional motives will also avoid using an obvious suspect classification.

127. 429 U.S. 252 (1977).

128. Id. at 269.

129. Id. at 270 .

130. Id. at 269-70; see Lotero, The Village of Arlington Heights: Equal Protection in the Suburban Zone, 4 Hastings Const. L.Q. 361, 373-74 (1977). 
We can envision several possible scenarios that demonstrate the possible process-distorting effects of unconscious racism on a governmental decision like that in Arlington Heights:

(1) The city council refused to rezone for the sole purpose of stigmatizing and denying housing to blacks. This case resembles Plessy $v$. Ferguson ${ }^{131}$ and Gomillion v. Lightfoot, ${ }^{132}$ in which the only motives were unconstitutional, and the ordinances were, therefore, per se unconstitutional. ${ }^{133}$

(2) The city claims a legitimate economic or environmental purpose, but evidence shows that it sought to exclude blacks in order to achieve that purpose. This case is the same as a classification by race on the face of a statute for which a legitimate goal is claimed. It is the case Ely describes where blacks are consciously excluded from the political process and devalued in the assessment of costs and benefits. When this self-conscious motive can be proved, the resulting classification is subject to strict scrutiny under existing doctrine. ${ }^{134}$

(3) The purpose of the ordinance was economic-i.e., to keep property values up by keeping poor people out-but the decisionmakers associated poverty with blacks and would have weighed the costs and benefits differently if the poor people they envisioned excluding were elderly white people on social security. This "selective sympathy or indifference" 135 could have occurred at a conscious or unconscious level. ${ }^{136}$ It is more than likely that the decisionmakers knew that the poor people they were excluding were black, but they would not be likely to have known that they undervalued the cost to poor people because they thought of them as black rather than white.

(4) A constituency within Arlington Heights-for example, elderly whites-did not actively campaign for the rezoning because of aversion to blacks who might have benefited from it. This occurred despite the fact that this constituency's interest in low income housing would otherwise have outweighed its interest in property values. This inability or unwillingness to apprehend and act upon an overlapping interest is precisely the kind of process distortion through group vilification that

131. 163 U.S. 537 (1896).

132. 364 U.S. 339 (1960).

133. In Gomillion, the Court set aside the Alabama legislature's action changing the shape of Tuskegee from a square to a "strangely irregular twenty-eight-sided figure," thereby removing from the city all but a handful of black voters but not one white. The Court found these facts " $[t]$ antamount for all practical purposes to a mathematical demonstration, that the legislation is solely concerned with . . f fencing Negro citizens out of the town." Id. at 341.

134. See Arlington Heights, 429 U.S. at 264-65; Washington v. Davis, 426 U.S. 229, 239-42 (1976).

135. "By the phenomenon of racially selective sympathy and indifference I mean the unconscious failure to extend to a minority the same recognition of humanity, and hence the same sympathy and care, given as a matter of course to one's own group." Brest, supra note 7, at 7-8.

136. See notes 231-238 infra and accompanying text. 
Ely describes. ${ }^{137}$ It is as likely as not that these elderly voters are largely unaware of the vilification and resulting aversion that preempted their potential coalition with blacks.

(5) No one in Arlington Heights thought about blacks one way or the other-i.e., it was a fight between environmentalists and developers-but an inadvertent devaluing of black interests caused inattention to the costs blacks would have to bear. If one asked the decisionmakers how they had valued the cost to blacks of the exclusionary zoning, they might have responded, "I never thought of that." This is an example of selective indifference or misapprehension of costs that occurs entirely outside of consciousness.

The process defect theory sees suspect classification doctrine as a roundabout way of uncovering unconstitutional motive by suspecting those classifications that disadvantage groups we know to be the object of widespread vilification. But by only suspecting laws that classify by race on their face or are the result of overtly self-conscious racial motivation, the theory stops an important step short of locating and eliminating the defect it has identified. ${ }^{138}$ Where a society has recently adopted a moral ethic that repudiates racial disadvantaging for its own sake, governmental decisionmakers are as likely to repress their racial motives as they are to lie to courts or to attempt after-the-fact rationalizations of classifications that are not racial on their face but that do have disproportionate racial impact. ${ }^{139}$ Unconscious aversion to a group that has historically been vilified distorts the political process no less than a conscious decision to place race hatred before politically legitimate goals.

Moreover, unconscious prejudice presents an additional problem in that it is not subject to self-correction within the political process. When racism operates at a conscious level, opposing forces can attempt to prevail upon the rationality and moral sensibility of racism's proponents; the self-professed racist may even find religion on the road to Damascus and correct his own ways. But when the discriminator is not aware of his prejudice and is convinced that he already walks in the path of righteousness, neither reason nor moral persuasion is likely to succeed.140 The process defect is all the more intractable, and judicial scrutiny becomes imperative.

\section{B. The Stigma Theory}

A second theory posits elimination of racially stigmatizing actions as

137. See note 121 supra and accompanying text.

138. See notes $16,46-111$ supra and accompanying texts.

139. See notes 76-91 supra and accompanying text.

140. Many blacks find it more difficult to deal with the self-convinced liberal than with the admitted racist in working for racial justice. See, e.g., M. KING, WHY WE CAN'T WAIT 87-93 (1963). 
the central concern of the equal protection clause. ${ }^{141}$ Under this theory, racial classifications should be strictly scrutinized when they operate to shame and degrade a class of persons by labeling it as inferior. ${ }^{142}$ Stigmatization is the process by which the dominant group in society differentiates itself from others by setting them apart, treating them as less than fully human, denying them acceptance by the organized community, and excluding them from participating in that community as equals. ${ }^{143}$ If the equal protection clause guarantees the right to be treated as an equal, 144 "the constitutional claim in question can be reduced to a claim to be free from stigma." 145 This theory acknowledges a historical experience in which the dominant group has systematically used stigmatizing labels against blacks and other nonwhites and has developed a social system of laws, practices, and cultural mores that looks down upon these groups, treating them as different from, and inferior to, the norm. ${ }^{146}$

The prevention of stigma was at the core of the Supreme Court's unanimous declaration in Brown $v$. Board of Education 147 that segregated public schools are inherently unequal. ${ }^{148}$ In observing that the segregation of black pupils "generates a feeling of inferiority as to their status in the community," 149 Chief Justice Warren recognized what a majority of the Court had ignored almost sixty years earlier in Plessy $v$. Ferguson: ${ }^{150}$ The social meaning of racial segregation in the United States is the designation of a superior and an inferior caste, and segregation proceeds "on the ground that colored citizens are ... inferior

141. See Strauder v. West Virginia, 100 U.S. 303 (1880) (striking down a state law excluding blacks from juries). In that case, Justice Strong, writing for the court, held that the fourteenth amendment protects blacks "from legal discriminations, implying inferiority in civil society," and that the West Virginia statute was "practically a brand upon them" and "an assertion of their inferiority." Id. at 308; see also Plessy v. Ferguson, 163 U.S. 537, 560, 562 (1896) (Harlan, J., dissenting) (referring to the segregation of railway passengers as a "badge of servitude" which proceeded "on the ground that colored citizens are ... inferior and degraded"); Brest, supra note 7, at 8-12; Karst, supra note 3, at 5-1 1; Karst, Why Equality Matters, 17 GA. L. REv. 245 (1983).

142. Regents of the Univ. of Cal. v. Bakke, 438 U.S. 265, 361-62 (1978) (Brennan, J., concurring in part and dissenting in part).

143. "Erving Goffman, in his profound little book on the subject, shows how stigmatization is a process by which we (the so-called 'normals') differentiate them (the stigmatized) from us, setting them apart and treating them as not quite human." Karst, supra note 141, at 248-49 (citing E. Goffman, Stigma: Notes on the Management of Spolled Identity 1-9 (1963)); see also Delgado, supra note 21, at 136-46.

144. See R. Dworkin, Taking Rights Seriously 227 (1977); L. Tribe, American ConSTITUTIONAL LAW 993 (1978).

145. Karst, supra note 141 , at 249.

146. See Black, The Lawfulness of the Segregation Decisions, 69 YALE L.J. 421,424 (1960); see also C. Woodward, The Strange Career of Jim Crow 31-65 (1966); Karst, supra note 141, at 274; Lawrence, Segregation "Misunderstood": The Milliken Decision Revisited, 12 U.S.F. L. REv. 15 (1977).

147. 347 U.S. 483 (1954).

148. "We conclude that in the field of public education the doctrine of 'separate but equal' has no place. Separate educational facilities are inherently unequal." Id. at 495.

149. Id. at 494 .

150. 163 U.S. 537 (1896). 
and degraded."151

Stigmatizing actions harm the individual in two ways: They inflict psychological injury by assaulting a person's self-respect and human dignity, ${ }^{152}$ and they brand the individual with a sign that signals her inferior status to others and designates her as an outcast. ${ }^{153}$ The stigma theory recognizes the importance of both self-esteem and the respect of others for participating in society's benefits and responsibilities. ${ }^{154}$

Proponents of this theory have also observed that racial stigma is self-perpetuating. Labeling blacks as inferior denies them access to societal opportunities; as a result, inadequate educational preparation, poverty of experience, and insufficient basic necessities limit their ability to contribute to society, and the prophecy of their inferiority is fulfilled. ${ }^{155}$ Furthermore, separate incidents of racial stigmatization do not inflict isolated injuries but are part of a mutually reinforcing and pervasive pattern of stigmatizing actions that cumulate to compose an injurious whole that is greater than the sum of its parts. ${ }^{156}$

The injury of stigmatization consists of forcing the injured individual to wear a badge or symbol that degrades him in the eyes of society. But in most cases the symbol is not inherently pejorative. Rather, the message obtains its shameful meaning from the historical and cultural context in which it is used and, ultimately, from the way it is interpreted by those who witness it. Thus the woman who is asked to use a separate public bathroom from her husband is unlikely to be stigmatized by that action: Our society does not ordinarily interpret sex-segregated toilet facilities as designating the inferiority of women. ${ }^{157}$ By contrast,

151. Id. at 560 (Harlan, J., dissenting); see also Black, supra note 146, at 427; Brest, supra note 7, at 8-9; Cahn, Jurisprudence, 30 N.Y.U. L. REv. 150, 158-59 (1955); Lawrence, supra note 146 , at 26 . Note that while formal, legally sanctioned segregation was the chief form of stigmatization prior to Brown and the Civil Rights Act of 1964, Pub. L. No. 88-352, 78 Stat. 241 (codified as amended at 28 U.S.C. $\$ 1447,42$ U.S.C. $\$ \S 1971,1975 a-1975 d, 2000 a-$ $2000 \mathrm{~h}-6$ (1982)), the system has yet to be dismantled, and other stigmatizing mechanismsincluding the exclusion of blacks from private clubs, privately enforced housing discrimination, and deprecating portrayals of blacks in the media-have reinforced its effects. See Lawrence, Negroes in Conlemporary Society, in MAN, Culture AND SocieTy 52, 59 (C. Lawrence ed. 1962). For a discussion of segregation as an institutionalized, self-perpetuating mechanism of stigmatization, see Lawrence, supra note 146.

152. See Delgado, supra note 21 , at $135-46$.

153. See id. at 135-37, 144-45; Lawrence, supra note 146, at 23-30.

154. See Karst, supra note 3, at 7 ('Inequality, when 'taken personally' as an index of personal worth, directly harms the primary good of self respect .... But the harms from stigma are not merely psychological. The society also acts toward the stigmatized person on the basis of the stigma."); see also Michelman, The Supreme Court, 1968 Term-Foreword: On Protecting the Poor Through the Fourleenth Amendment, 83 HARv. L. REv. 7, 49 (1969).

155. See Delgado, supra note 21, at 139-42, 146-47; Lawrence, supra note 146, at 37-38. Gunnar Myrdal has identified the circular, self-perpetuating nature of racial prejudice and discrimination as the principle of "cumulative causation." See G. MYRDal, supra note 62, at 7576; see also Lawrence, supra note 151, at 55-56.

156. See Brest, supra note 7, at 10-12; see also Delgado, supra note 21, at 146; Karst, supra note 3 , at 50-51.

157. Wasserstrom, supra note 22 , at 593. 
the black who is asked to use a different public bathroom from that of a white companion of the same gender is stigmatized. As Richard Wasserstrom has noted, racially segregated bathrooms were an important part of the system of segregation. That system's ideology held not only that blacks were less than fully human but also that they were dirty and impure. Racially segregated bathrooms ensured that blacks would not contaminate the facilities used by whites. ${ }^{158}$

If stigmatizing actions injure by virtue of the meaning society gives them, then it should be apparent that the evil intent of their authors, while perhaps sufficient, is not necessary to the infliction of the injury. ${ }^{159}$ For example, a well-meaning if misguided white employer, having observed that her black employees usually sat together at lunch, might build a separate dining room for them with the intent of making them more comfortable. This action would stigmatize her black employees despite her best intentions. ${ }^{160}$ Similarly, when the city of Jackson, Mississippi closed its public pools after a federal court ordered it

\section{Id. at 592 .}

159. Professor Larry Simon has argued that the constitutional harm of stigma cannot exist without reference to the motive of the actor who has inflicted the alleged result. Simon, Racially Prejudiced Governmental Actions, 15 San Diego L. Rev. 1041, 1052-53 (1978).

The difference between insult as a synonym for hurt feelings and as a normative term seems to be this: We regard actions taken by others as insults in the latter sense only when, in addition to having hurtful effects upon self-respect or pride, we infer that the actor made the statement partly because he disliked us or wanted to hurt our feelings. Thus, the context in which another acts or speaks often determines whether we regard it as insulting. A friend might criticize someone with the avowed goal of helping her get along better with others. The criticism might hurt her friend's feelings, but it would not be understood as an insult so long as the one criticized accepted her friend's account of her goal or motive. If an enemy had made the same statement without explanation, it might well be taken as an insult. In other words, insult and cognate terms imply assessments of attitudes or goals-hence the excusing phrase "not intended as an insult." Consequently, if a third person (or a court) were called in to resolve a disagreement about whether one person had insulted another, the arbiter could not perform this task without assessing the attitudes or goals that underlie the action at issue.

Id.

Simon's analysis incorrectly identifies the governmental actor's injurious intent as distinguishing mere "hurt feelings" from the normative injury of stigma. The contextual factor that is crucial in determining the presence of stigma is not the actor's intent but the meaning others will give the actor's words or actions. A friend's criticism might be made with benign motives, but if an observing public understands the words as derogatory, the lack of intent is irrelevant. Likewise, an intended insult that is understood as benign or disregarded by others will not be stigmatizing. Simon notes that "some actions or statements become, through experience, so identified with racial prejudice that we regard them as almost per se racially insulting; but this phenomenon occurs only because our experience suggests that such actions or statements rarely are taken or made apart from racially prejudiced attitudes. The word nigger is an example." Id. at 1053. But the word "nigger" is almost always stigmatizing, because third parties as well as the individual to whom it is directed will almost always give it a derogatory meaning. That it is almost always intended as an insult may determine the meaning it is given, but it is not the significant source of the stigma. See notes 177-296 infra and accompanying text.

160. Cf. note 292 infra (noting some situations where racially segregated facilities may not be given stigmatizing meaning). 
to integrate them, ${ }^{161}$ the action stigmatized blacks regardless of whether the government's purpose was racial or economic.

Given that stigma occurs whether there is racial animus or not, the answer to our initial question, "Is knowledge about the intent of the governmental actor significant to the achievement of the equal protection clause's purpose?" would seem an obvious "No." But many of the stigma theory's advocates find themselves in a quandary when faced with the question of how the Court should approach laws that are not apparently "race-dependent" 162 but that result in disparate and stigmatizing effects. Kenneth Karst, for example, notes the Supreme Court's recent inhospitality to constitutional claims of disproportionate effect ${ }^{163}$ and argues that "[s]urely it is still a responsible form of advocacy to argue that some racially disproportionate effects of governmental action ought to be subjected to judicial scrutiny at a level higher than minimum rationality." 164 He does not, however, elaborate on how the Court should determine which cases to include among that "some." 165 Moreover, the origin of his reluctance to advocate increased scrutiny of all racially discriminatory impact lies in the disproportionate presence of blacks among the poor. He argues that, because the persistence of a racially identifiable economic underclass is probably beyond the capacity of courts to remedy, it is unrealistic to expect the Supreme Court to endorse this increased use of strict scrutiny in the near future. ${ }^{166}$

Similarly, Paul Brest, having persuasively argued the need to eliminate racially disproportionate impact that stigmatizes, ${ }^{167}$ cautions that the impact doctrine "cannot reasonably be applied across the board" and urges that the doctrine be used "selectively." $168 \mathrm{He}$ warns that "remedies for disproportionate impact may impose heavy costs on in-

161. See Palmer v. Thompson, 403 U.S. 217 (1971).

162. I refer to Professor Brest's use of the term "race-dependent," which includes "decisions and conduct ... that would have been different but for the race of those benefited or disadvantaged by them." Brest, supra note 7, at 6 .

163. Karst, supra note 141 , at 275.

164. Id. (emphasis added).

165. Karst identifies some effect cases he would subject to a higher level of scrutiny. He refers to Brest's Defense of the Antidiscrimination Principle, supra note 7, at 10-11; Eisenberg's Disproportionate Impact and Illicit Motive, supra note 5, at 36; and his own Equal Citizenship, supra note 3, at 49-52. Karst, supra note 141, at 275 n.146. But each of these authors proposes a somewhat different approach. Compare Eisenberg, supra note 5, at 89-98 (criticizing Brest's view) with Brest, supra note 7, at 6-53.

166. Karst, supra note 141 , at 275.

167. For Brest, the intent requirement is especially troubling in those cases where racedependent decisions are strongly suspected but cannot be proved or where the stignatic harm of past intentional discrimination continues into the present. See Brest, supra note 7, at 28-29, 35-36.

168. Id. at 29. Brest argues that the disproportionate impact doctrine sometimes serves the antidiscrimination principle by creating a rebuttable presumption of intentional discrimination. But he stops short of applying a pure uneven impact test "for the reasons suggested by Mr. Justice White's parade of horribles in Washington v. Davis." Id. Instead, he expressly applies the presumption only in school desegregation and employment discrimination cases. Id. at $29-30$. 
stitutions and individuals, and cannot be tailored narrowly to compensate all those and only those whose present situation is the result of past discrimination." 169 Brest's reference to the overbreadth of remedies for disproportionate impact adds to the general concern about unduly limiting legislative discretion and the particular concern about the legitimacy of courts imposing costs on "blameless" individuals and conferring benefits on those who have not been directly harmed. ${ }^{170}$

The consideration of unconscious intent responds to both of these concerns. Identifying stigmatizing actions that were affected by the actor's unconscious racial attitudes achieves two benefits. First, it significantly decreases the absolute number of impact cases subject to heightened scrutiny without eviscerating the substantive content of the equal protection clause. The bridge toll, the sales tax, and the filing fee can no longer be numbered among the parade of horribles that Justice White suggested in Davis. ${ }^{171}$ At the same time, cases where racially discriminatory impact results directly from past intentional discrimination or from current but unprovable racial animus will be well within judicial reach. ${ }^{172}$ A law does not stigmatize blacks simply because exclusion itself is stigmatizing, and, in this instance, they are disproportionately represented among the excluded group. Instead, the stigma stems at least in part from society's predisposition to exclude blacks. ${ }^{173}$ The fact that unconscious racial attitudes affected a governmental action is evidence that the racially stigmatizing symbolism preexisted the present impact.

Second, consideration of unconscious motivation provides a neutral principle for judicial intervention-i.e., the identification of a process defect. ${ }^{174}$ This counters the argument made against the impact test that the judiciary has no principled basis for imposing a priority for the removal of racial stigma over other social goods to which the political branch might choose to give preeminence. In short, stigma often occurs regardless of the intent of those who have engaged in the stigmatizing action. Thus, it is arguable that under the stigma theory neither

169. Id. at 36; see also N. GLAZER, supra note 31 .

170. See note 10 supra and accompanying text; see also Jefferson v. Hackney, 406 U.S. 535, 545-51 (1972) (holding that the fourteenth amendment does not require AFDC funding reductions to be equal to those of other government benefit programs so long as the legislature's judgment is not "invidious or irrational").

171. 426 U.S. 229, 248 \& n.14 (1976) (citing Goodman, supra note 10, at 300); see also notes 225-228 infra and accompanying text.

172. These are the two areas where Brest expresses particular concern about the need for an impact test. Brest, supra note 7, at 28-31.

173. For example, there is an important distinction between stigma that is given racial meaning by a present contextual setting (i.e., a higher percentage of blacks are excluded from a neighborhood because a higher percentage of blacks are poor and the cost of housing excludes them) and stigma that is also influenced by blacks' previous racial stigmatization (i.e., a higher percentage of blacks are excluded from a neighborhood because the cost of housing excludes the poor and because it is a neighborhood where blacks have previously been excluded solely because of their race). See notes 209-228 infra and accompanying text.

174. See notes 297-322 infra and accompanying text. 
conscious nor unconscious intent should be considered, and heightened judicial scrutiny should apply in all cases when governmental action produces a stigmatizing effect. Nonetheless, recognizing unconscious racism provides a mechanism for effectively responding to continuing race-based inequalities while minimizing the costs of judicial overreaching.

While the cultural meaning test identifies the same elements of the injury of racial discrimination as does the stigma theory, it differs from that theory in two regards. First, it identifies the injury at a different point in the constitutional analysis. The stigma theory explains why recognized racial classifications-i.e., laws whose racial classification is apparent on their face or laws whose racial motive has been provedshould be subject to heightened judicial scrutiny. In noting that the harm of stigma occurs irrespective of the presence of conscious motive, the cultural meaning test refocuses the stigma theory's inquiry to a different point in time. The presence of racial stigma is viewed as evidence of the existence of a racial classification, not simply as a justification for the heightened scrutiny of such classifications. ${ }^{175}$

Second, the cultural meaning test adds content to the stigma theory's analysis. It locates the origin of racial stigma in the accumulation of the individual unconscious and finds the origin of unconscious racism in the presence of widely shared, tacitly transmitted cultural values. ${ }^{176}$ The recognition of these mutually reciprocal origins joins the theoretical description of human action as arising out of autonomous individual choice with the view that such action is socially determined. The cultural meaning theory thus describes a dialectic rather than a dichotomy. It demonstrates that ultimately the proponents of the process defect theory and the stigma theory have identified different manifestations of the same cultural phenomenon.

\section{Reading the Mind's Symbols: How Do We Identify Unconscious Racism in SPEcific Cases?}

\section{A. The "Cultural Meaning" Test}

This article's discussion of the stigma theory has anticipated the third likely challenge to my thesis that equal protection doctrine must address the unconscious racism that underlies much of the racially disproportionate impact of governmental policy. This challenge questions how a court would identify those cases where unconscious racism operated in order to determine whether to subject an allegedly discriminatory act to strict scrutiny.

I propose a test that would look to the "cultural meaning" of an allegedly racially discriminatory act as the best available analogue for

175. See notes 177-187 infra and accompanying text.

176. See notes 55-91 supra and accompanying text. 
and evidence of the collective unconscious that we cannot observe directly. This test would evaluate governmental conduct to see if it conveys a symbolic message to which the culture attaches racial significance. The court would analyze governmental behavior much like a cultural anthropologist might: by considering evidence regarding the historical and social context in which the decision was made and effectuated. If the court determined by a preponderance of the evidence that a significant portion of the population thinks of the governmental action in racial terms, then it would presume that socially shared, unconscious racial attitudes made evident by the action's meaning had influenced the decisionmakers. As a result, it would apply heightened scrutiny. ${ }^{177}$

The unconscious racial attitudes of individuals manifest themselves in the cultural meaning that society gives their actions in the following way: In a society that no longer condones overt racist attitudes and behavior, many of these attitudes will be repressed and prevented from reaching awareness in an undisguised form. ${ }^{178}$ But as psychologists have found, repressed wishes, fears, anger, and aggression continue to seek expression, most often by attaching themselves to certain symbols in the external world. ${ }^{179}$ Repressed feelings and attitudes that are commonly experienced are likely to find common symbols particularly fruitful or productive as a vehicle for their expression. Thus, certain actions, words, or signs may take on meaning within a particular culture as a result of the collective use of those actions, words, or signs to represent or express shared but repressed attitudes. ${ }^{180}$ The process is cyclical: The expression of shared attitudes through certain symbols gives those symbols cultural meaning, and once a symbol becomes an enduring part of the culture, it in turn becomes the most natural vehicle for the expression of those attitudes and feelings that caused it to become an identifiable part of the culture. ${ }^{181}$

177. We can assume that governmental officials are well-integrated members of the culture-not deviants-and that they, therefore, share the collective unconscious.

178. See notes 55-75 supra and accompanying text.

179. See J. Kovel, supra note 21 , at 93-105. See generally S. Freud, Civilization and ITS Discontents, in 21 The Complete Works, supra note 46, at 59; H. Marcuse, One-DimenSional MaN (1964); H. Marcuse, ERos and Givilization (1955).

180. See note 179 supra.

181. Dr. Margaret Lawrence has summarized Dr. Sandor Rado's observations, together with her own, regarding the source of "dated emotions" and their role in the creation of cultural meaning. Sandor Rado used the term "dated emotions" to refer to those "nonreporting" or unconscious aspects of the mind that eventually find outlets in the daily life of an individual, including his cultural attitudes:

"Dated emotions" have their origin early in the life of the individual and represent a child's feeling response or responses in his or her day to day relationships with the parent....

These early emotions are for good reason kept out of awareness ....

Emotional responses so derived remain intact during the child's development to adult life but on a level of unawareness. They erupt throughout life as dated emotions with teachers, husband, and therapist. ...

"Dated emotions" may find their object in a group setting in identification with group attitudes towards a common enemy or in identification with a common cause. Members of the 
Cognitive theory provides an alternative explanation of why the racial meaning the culture gives an action will be evidence of the actor's unconscious racial motivation. According to cognitive theory, those meanings or values that are most deeply ingrained in the culture are commonly acquired early in life through tacit lessons. They are, therefore, less recognizable and less available to the individual's consciousness than other forms of knowledge. Looked at another way, if the action has cultural meaning, this meaning must have been transmitted to an individual who is a member of that culture. If he professes to be unaware of the cultural meaning or attitude, it will almost surely be operating at an unconscious level. ${ }^{182}$

Thus, an action such as the construction of a wall between white and black communities in Memphis ${ }^{183}$ would have a cultural meaning growing out of a long history of whites' need to separate themselves from blacks as a symbol of their superiority. Individual members of the city council might well have been unaware that their continuing need to maintain their superiority over blacks, ${ }^{184}$ or their failure to empathize with how construction of the wall would make blacks feel, influenced their decision. ${ }^{185}$ But if one were to ask even the most self-deluded

group share common symbols which are universal defensive choices, related to their own dated emotions. In his various roles in society the individual's dated emotions generationally achieved contribute to the society, its history and the culture to which the individual belongs. Of this the individual is for the most part unaware ....

Letter from Margaret Morgan Lawrence to Charles R. Lawrence III (Oct. 5, 1985) (includes summary of her notes from unpublished lectures delivered by Sandor Rador at the Columbia Psychoanalytic Center, New York, New York, 1948-1951) (on file with author).

182. See notes $76-91$ supra and accompanying text. A theory that views stigma as the chief substantive harm against which the equal protection clause is directed might well adopt a racial meaning test without attempting to demonstrate a connection between the unconscious of the decisionmaker and the meaning society attaches to his action. Under such a theory, intent is arguably irrelevant. It is sufficient that the meaning given the action further expands the pervasive system of racial stigma. See notes 141-176 supra and accompanying text.

183. City of Memphis v. Greene, 451 U.S. 100 (1981).

184. Several scholars have criticized Memphis as a poor application of the intent test:

The closing was effected by the erection of a barrier at the point of separation between the black and white neighborhoods. It was a unique step, not part of a uniform city planning effort, taken at the request of white property owners who expressed concern about excess traffic and danger to children. One person soliciting signatures for a petition in favor of the street closing had referred to the traffic as "undesirable traffic."

The Court refused to probe beneath the surface of the residents' expressed purposes, asserting that, because the plaintiffs had sued the mayor and city council, it is the latter's motivation that must be ascertained. The Court similarly refused to hold that the history of resistance to desegregation in Memphis, the fact that the white neighborhood in question developed as a result of pre-World War II segregation, and evidence of present racial animus required the district court to find that the city council's action was racially motivated, since there was no showing that "the residents of Hein Park would have welcomed the heavy flow of transient traffic through their neighborhood if the drivers had been predominantly white."

Weinzweig, supra note 5 , at 330 .

185. Even whites who might admit in an unguarded moment of candor that they continue to harbor feelings of superiority over blacks would be likely to have convinced them- 
among them what the residents of Memphis would take the existence of the wall to mean, the obvious answer would be difficult to avoid. ${ }^{186}$ If one told the story leading to the wall's construction while omitting one vital fact-the race of those whose vehicular traffic the barrier excluded-and then asked Memphis citizens to describe the residents of the community claiming injury, few, if any, would not guess that they were black.

The current racial meanings of governmental actions are strong evidence that the process defects of group vilification and misapprehension of costs and benefits have occurred whether or not the decisionmakers were conscious that race played a part in their decisionmaking. Moreover, actions that have racial meaning within the culture are also those actions that carry a stigma for which we should have special concern. This is not the stigma that occurs only because of a coincidental congruence between race and poverty. The association of a symbol with race is a residuum of overtly racist practices in the past: The wall conjures up racial inferiority, not the inferiority of the poor or the undesirability of vehicular traffic. And stigma that has racial meaning burdens all blacks and adds to the pervasive, cumulative, and mutually reinforcing system of racial discrimination. ${ }^{187}$

\section{B. Cultural Meaning as Social Text}

Some may question the competence of courts to apply a test that asks them to interpret the meaning of human behavior. Although some legal scholars have warmly embraced economics, most remain skeptical about the utility of social sciences and the ability of courts to understand and interpret complex social science data. But the interpretation of cultural meaning is not so foreign a task for courts as it first appears. Indeed, construction of text is the most basic of judicial tasks. And while most judicial interpretation involves determining the meaning of written text, legal theorists have recognized that meaningful human behavior can be treated as a "text-analogue." 188 The context in which both written and social text is read can give it meaning beyond its authors' original intention: ${ }^{189}$ The social text of human action, like the

selves that this particular decision was not influenced by those feelings. Justice Stevens' opinion in Memphis is itself an example of how a decision need not involve self-conscious racial animus to be race-dependent. Stevens' failure to recognize racial intent in the Memphis city council's decision is certainly not the result of conscious racial bias, but it may well be the product of unconscious selective sympathy.

186. See Black, supra note 146 , at 424 .

187. See note 156 supra; notes 209-224 infra and accompanying text.

188. See Grey, The Constitution as Scripture, 37 STAN. L. REv. 1, 4-5 (1984).

189.

In spoken discourse, the subjective intention of the speaker and the objective meaning of the discourse overlap, while with written discourse the meaning of the text is disassociated from the mental intention of the author and the two no longer coincide. Likewise, spoken discourse ultimately refers to the contextual situation common to the speaker and the listener. Texts, on the other hand, speak about the 
written text, is judged not just by those who are present when it takes place but by all who come to know of it. ${ }^{190}$

In fact, courts frequently interpret the meaning of social phenomena. In establishment clause cases, the Court determines whether a governmental practice advances or inhibits religion by inquiring into the meaning the culture gives that practice: When a municipality includes a creche in its annual Christmas display, will most observers understand the creche as "a symbol of Christian beliefs and a symbol of the city's support for those beliefs," 191 or will they interpret the display as merely depicting "the historical origins of [a] traditional event long recognized as a National Holiday"? 192 In determining the scope of the "zones of privacy"193 that the fourteenth amendment's due process clause protects, the Court has interpreted the concept of the family by referring to the meaning that the history and traditions of our culture have given it. ${ }^{194}$ The Court has also defined the scope of the fourth amendment's protection against warrantless search and seizure by asking whether an individual has a "reasonable expectation of privacy" in the searched premises. ${ }^{195}$

world. The text frees itself from the reference of the particular situation in which its author speaks and creates its own universe of references.

P. Ricoevr, Hermeneutics ANd the HuMan SCIENCEs 200-02 (1981); see also Taylor, Interpretation and the Sciences of Man, in UNDERSTANDING aNd Social. InQuiry 101 (F. Dallmayr \& $\mathrm{T}$. McCarthy eds. 1977).

190. See Brest, Interpretation and Interest, 34 STAN. L. REv. 765, 767-68 (1982). See generally P. RicoevR, supra note 189. In the same way that a text is detached from its author, an action is detached from the actor and develops consequences of its own. This autonomy of human action constitutes the social dimension of action.

To what extent may we say that what is done is inscribed? Certain metaphors may be helpful at this point. We say that such-and-such event left its mark on time. We speak of marking events. Are not there "marks" on time, the kind of thing which calls for a reading, rather than for a hearing?

Id. at 205-06. Furthermore, action shares with text the characteristic of being addressed to an infinite range of possible readers or interpreters.

[L]ike a text, human action is an open work, the meaning of which is "in suspense."

It is because it "opens up" new references and receives fresh relevance from them, that human deeds are also waiting for fresh interpretations which decide their meaning. All significant events and deeds are, in this way, opened to this kind of practical interpretation through present praxis. Human action, too, is opened to anybody who can read.

Id. at 208.

191. Lynch v. Donnelly, 465 U.S. 668, 705 (1984) (Brennan, J., dissenting).

192. Id. at 680; see also Stone v. Graham, 449 U.S. 39 (1980) (statute requiring posting of ten commandments on public school classroom walls); School Dist. v. Schempp, 374 U.S. 203 (1963) (Bible reading as opposed to Bible study).

193. Roe v. Wade, 410 U.S. 113,152 (1973).

194. See, e.g., Moore v. City of East Cleveland, 431 U.S. 494, 503-05 (1977) (finding that a municipal housing ordinance that limited occupancy of a dwelling unit to certain categories of family members unnecessarily intruded upon the freedom of personal choice in matters of family life: "Ours is by no means a tradition limited to respect for the bonds uniting the members of the nuclear family. The tradition of uncles, aunts, cousins, and especially grandparents sharing a household along with parents and children has roots equally venerable and equally deserving of constitutional recognition.").

195. Katz v. United States, 389 U.S. 347, 360 (1967) (Harlan, J., concurring); see, e.g., 
In considering the constitutionality of statutes and regulations challenged on sex discrimination grounds, the Court has held that the legislature may not make overbroad generalizations that "demean the ability or social status of the affected class."196 It determines whether legislation transgresses this prohibition by asking whether the law "tends to perpetuate the stereotyped view" of women. ${ }^{197}$ This question is not answered by determining whether the legislature intended to stereotype women but by interpreting the contemporary community consensus regarding the message the legislation conveys-that is, its cultural meaning. The legislation can only perpetuate a stereotype if it triggers existing preconceptions in the culture: men as breadwinners and women as dependents, ${ }^{198}$ men as property managers and women as homemakers, ${ }^{199}$ young men as sexually aggressive and women as weak and in need of protection, ${ }^{200}$ women as nurses and men as not. ${ }^{201}$

Given that courts engage in cultural anthropological inquiry so often, why is there such resistance to a similar inquiry in racial discrimination cases? One possible explanation lies in the fact that social scientists can rarely prove the causal relationships that support their hypotheses. For example, courts have looked to social science to prove whether or not integrated schools will improve the educational achievement of black children ${ }^{202}$ and whether or not differential school expenditures will make a difference in students' educational opportunities. ${ }^{203}$ Our misgivings about allowing judicial decisions to turn on social science evidence are prompted, in large part, by social

California v. Carney, 471 U.S. 386 (1985) (anthropological inquiry into whether a "Dodge Mini Motor Home" is a vehicle or a home).

196. Michael M. v. Superior Court, 450 U.S. 464, 469 (1981) (quoting Parham v. Hughes, 441 U.S. 347, 354 (1979)).

197. Mississippi Univ. for Women v. Hogan, 458 U.S. 718, 729 (1982).

198. Frontiero v. Richardson, 411 U.S. 677, 681 (1973). (1971).

199. Kirchberg v. Feenstra, 450 U.S. 455,459 (1981); Reed v. Reed, 404 U.S. 71, 74

200, Michael M., 450 U.S. at 467-69.

201, Hogan, 458 U.S. at 723-27.

202. Despite the centrality of social science research in the Court's opinion in Brown I, see note 204 infra, courts have rarely relied directly upon social science research to determine whether segregation is unconstitutional. They have, however, referred to social science research in determining the nature and extent of remedies. See Levin, School Desegregation Remedies and the Role of Social Science Research, 42 Law \& Contemp. Probs. 1 (1978). The social science literature on the effects of desegregation is immense. For an overview of this literature, see D. Kirp \& M. Yudof, Educational Policy and the Law 494-507 (2d ed. 1982).

203. Serrano v. Priest, 18 Cal. 3d 728, 557 P.2d 929, 135 Cal. Rptr. 345 (1976), cert. denied, 432 U.S. 907 (1977); see also Lujan v. Colorado State Bd. of Educ., 649 P.2d 1005 (Colo. 1982) (en banc); Horton v. Meskill, 172 Conn. 615, 376 A.2d 359 (1977); Caldwell v. State, No. 50616 (Johnson County Dist. Ct., Kan., Aug. 30, 1972); Robinson v. Cahill, 62 N.J. 473, 303 A.2d. 273, cert. denied, 414 U.S. 976 (1973); Board of Educ. v. Nyquist, 94 Misc. 2d 466, 408 N.Y.S.2d 606 (1978), modified, 83 A.D.2d 217, 443 N.Y.S.2d 843 (1981), modified, 57 N.Y.2d 27, 439 N.E.2d 359, 453 N.Y.S.2d 643 (1982), appeal dismissed, 459 U.S. 1138 (1983); Pauley v. Kelly, 162 W. Va. 672, 255 S.E.2d 859 (1979); Washakie County School Dist. No. 1 v. Herschler, 606 P.2d 310 (Wyo. 1980). 
science's inability to prove or disprove such propositions. ${ }^{204}$

If the proposed cultural meaning test required the courts to rely upon social scientists to conclusively demonstrate causal relationships between challenged governmental actions and harm to blacks, it would be subject to similar criticism concerning the inadequacy of social science methodology. But there is another kind of judgment or analysis that historians, economists, sociologists, anthropologists, and other social scientists make. This is interpretive judgment. As Ronald Dworkin has explained, causal judgments assert a causal connection between two independently specifiable social phenomena. An interpretive judgment, on the other hand, locates a particular phenomenon within a category of phenomena by specifying its meaning in the society within which it occurs. ${ }^{205}$

Two of the more successful defenders of the Brown decision, Charles Black and Edgar Cahn, have argued that the question of the Court's reliance on social science evidence was beside the point: The constitutional rights at stake rested not upon that evidence but upon the insulting and degrading quality of segregation itself. ${ }^{206}$ But Dworkin points out that to argue that segregation is unconstitutional because it is an insult is not to argue that Brown was based on a value judgment distinct from a social science judgment. He notes that what Black and Cahn meant was that the decision rested on interpretive, not causal, judgments. To say that we don't need evidence for the proposition that segregation is an insult to the black community is not to say that we don't need to know it or that there is nothing to know. "There is a fact of the matter, namely that segregation is an insult, but we need no evidence for that fact-we just know it. It's an interpretive fact."207

It is this type of interpretive judgment that the cultural meaning test requires. The search for cultural meaning is necessarily an interpretive task. The distinction between causal and interpretive analysis is crucial,

204. Social scientists typically argue for or against causal judgments by means of statistical correlations. Physical scientists, in contrast, can usually produce a mechanical model that explains cause and effect. When causal judgments are based upon correlations among observed phenomena, an element of arbitrariness is necessarily introduced by the choice of categories that are correlated and by the selection of samples from which the data is gathered. Moreover, the data or behavior that produce the correlation are subject to rapid change.

One example of this kind of criticism of the judicial use of social science data was the reaction to the Brown Court's reliance on data produced by social psychologist Dr. Kenneth Clark about the effects of school segregation on the self-image of black children. See Brown v. Board of Educ., 347 U.S. 483, 494 n.1 1 (1954) (citing K. Clark, Effect of Prejudice and Discrimination on Personality Development (Mid-century White House Conference on Children and Youth, 1950)). Chief Justice Warren was attacked for "relying more on social scientists than on legal precedents." See R. KLUGer, Simple Justice 711 (1976) (quoting columnist James Reston as saying that "[t]he Court's opinion read more like an expert paper on sociology than a Supreme Court opinion").

205. Dworkin, Social Sciences and Constitutional Rights: The Consequences of Uncertainty, 6 J.L. \& EDUC. 3 (1977) (noting that causal and interpretive judgments are not mutually exclusive but are distinguishable, and that the distinction is important).

206. See id. at 5, 21; see also Black, supra note 146; Cahn, supra note 151, at 157-68.

207. Dworkin, supra note 205, at 5 . 
because the objections to the use of social science evidence to prove causal relationships do not apply to interpretive judgments such as the judgment that a particular practice will have a racially insulting meaning. Moreover, much of what judges do entails this kind of interpretation: It requires the same skills they employ when they decide a case by characterizing or interpreting a line of precedent in the way that seems most true to them. ${ }^{208}$

\section{Some Easy Cases}

Applying the cultural meaning test to a series of cases is the best way to examine its operative effect. ${ }^{209}$ These first cases are "easy" in that there will be little disagreement about whether the governmental action in question has racial meaning in our culture. They are cases like the segregated beach, which clearly has racial meaning, and the increased bridge toll, which clearly does not. These cases are instructive for two reasons: The lack of ambiguity in the meaning that will attach to the governmental action allows us to see more clearly the relationship between cultural meaning and unconscious intent; furthermore, these cases demonstrate the usefulness of a test that distinguishes governmental actions that have racial meaning in addition to racially disparate impact from those that have only racially disparate impact.

\section{Brown v. Board of Education. ${ }^{210}$}

Charles Black first discussed the "social meaning" of segregation in his brilliantly simple and succinct defense of Brown, The Lawfulness of the Segregation Decisions. ${ }^{211}$ He begins with history, ${ }^{212}$ and notes that segregation was the direct descendant of slavery and the black codes and an "integral part of the movement to maintain white supremacy."213 Segregation was not a case of mutual separation but a system that one group imposed on another. Black points to its contextual association

208. Several authors have argued that the judiciary's task is and should be interpretive. See, e.g., Dworkin, Hard Cases, 88 HARv. L. Rev. 1057 (1975); Grey, Do We Have an Unwrillen Constitution?, 27 Stan. L. Rev. 703 (1975). More recently, Grey has argued that all plausible constitutional theories are "interpretivist." See Grey, supra note 188; see also Brest, The Misconceived Quest for the Original Understanding, 60 B.U.L. REv. 204, 204 n.I (1980).

209. I have used both real and hypothetical cases to facilitate my discussion.

210. 347 U.S. 483 (1954).

211. Black, supra note 146 .

212. Actually, he begins with "laughter" at the idea that anyone could seriously advance the argument that segregation could provide equal treatment. Black then refers to his own experience:

I was raised in the South, in a Texas city where the pattern of segregation was firmly fixed. I am sure it never occurred to anyone, white or colored, to question its meaning. The fiction of "equality" is just about on a level with the fiction of "finding" in the action of trover. I think few candid southerners deny this.

Id. at 424 .

213. Id. at 424-25. 
with other "indisputably and grossly" discriminatory practices, such as exclusion from the vote, and to the manner in which segregation as a pattern of law often combined with extralegal patterns of discrimination. ${ }^{214}$ That "separate but equal" facilities were almost never really equal is evidence not just of the material inequality they imposed but also of the meaning of segregation to the people who imposed it..15 He cites the facts that it was actionable defamation in the South to call a white man a Negro and that "a small proportion of Negro 'blood' put one in the inferior race for segregation's purposes" as further evidence of segregation's meaning. ${ }^{216}$

Professor Black closes his catalogue of particulars with the observation that the points he has made "are matters of common knowledge, matters not so much for judicial notice as for the background knowledge of educated men who live in the world."217 Given this common knowledge, it is difficult, if not impossible, to envision how a governmental decisionmaker might issue an order to segregate without intending, consciously or unconsciously, to injure blacks. Could the defendants in Brown have escaped this meaning? Could anyone who grew up in the system Charles Black describes have made a decision to put black and white children in separate schools without that decision being influenced by race?

The "common knowledge," or clear meaning, Black describes is evidence of shared cultural attitudes that have expressed themselves in cultural symbols. The actions involved could have nothing other than a racial meaning within our society. ${ }^{218}$ But for purposes of our present analysis, the most important thing to recognize is that an action's meaning derives from a long-term and pervasive association of certain feelings or thoughts with that action. Feelings and thoughts that have become sufficiently widespread and internalized to express themselves in a system of social symbols or meanings do not disappear with the enactment of civil rights legislation. The feelings may be repressed from consciousness, but so long as the symbols they have created retain their meaning, the feelings continue to exist and to shape behavior.

\section{Memphis v. Greene. ${ }^{219}$}

This case is almost as easy as Brown. Memphis is a city whose public facilities were segregated by law until 1965. It has the same historical background as that described by Professor Black, and its social mores

214. Id. at 425. Although these extralegal patterns of discrimination are generally not state actions, they can nevertheless assist us in understanding the meaning and assessing the impact of state actions.

215. See notes 147-151 supra and accompanying text.

216. Black, supra note 146 , at $425-26$.

217. Id. at 426 .

218. See Washington v. Davis, 426 U.S. 229, 242-43, 244 n.12 (1976) (citing cases where impact is sufficient to demonstrate intent).

219. City of Memphis v. Greene, 451 U.S. 100 (1981). 
have changed only slightly in the twenty-five years since Black wrote. ${ }^{220}$ What does it mean to construct a barrier between all-white and all-black sections of Memphis? In a city where just twenty years ago such barriers were built down the middle of rest rooms and restaurants with signs on them that read "white" and "colored," won't there be considerable consensus as to whether the barrier speaks in racial terms? Won't there be a cultural memory that gives the barrier the same meaning even in the absence of the now-outlawed signs? ${ }^{221}$ Is it possible that a council member in this city would not have remembered the message conveyed by those earlier barriers when he voted to construct the present one?

I think it is impossible. ${ }^{222}$ Race cannot have been irrelevant in a decision that all know has a racial meaning-one that signifies the inferiority of blacks. That meaning says that the peace and quiet of a white neighborhood has been weighed against the stigmatization of blacks. The decision to build the barrier issues the statement that white tranquility is more important than black pride. In the contextual reality of Memphis, the message is as clear as if the declaration were painted on the wall itself.

This is a racial classification; as a consequence, it has a much greater constitutional significance than either a declaration that rich people's tranquility is more important than poor people's pride 223 or a declaration that downtown residents' tranquility is more important than uptown residents' vehicular access. ${ }^{224}$ If the governmental decisionmaker has somehow blinded herself to the inevitable intrusion of the issue of race on the process by relegating the issue to her unconscious, the court should not follow suit.

\section{Nonracial actions.}

At the opposite end of the spectrum is a hypothetical increase in the municipal railway fare in a racially and economically diverse municipality. It may be more burdensome on the relatively poor person who must use that transportation than on the relatively rich individual. It may also be true that nonwhites are disproportionately represented among the poor and that, therefore, the increase has a racially disparate

220. See Henderson, $A$ Failed Revolution: Civil Rights in the South; Jim Crow Lives On in Dixie, S.F. Examiner, Apr. 6, 1982, at 4, col. 1.

221. Like the "freedom of choice" plan struck down in Green v. County School Bd., 391 U.S. 430 (1968), the signs have been removed, but those who live in the county will continue to see "white" and "colored" schools. See Lawrence, supra note 146, at 34-39 (criticizing Green in light of the history of segregation).

222. The council member may, however, have repressed the memory of this message in his decision to construct the wall.

223. Unlike classifications based on race, wealth classifications have been held not suspect. See San Antonio School Dist. v. Rodriguez, 411 U.S. 1 (1973).

224. The Supreme Court minimally scrutinizes laws that are racially neutral and that regulate economic activity. See, e.g., Williamson v. Lee Optical Co., 348 U.S. 483 (1955); Railway Express Agency v. New York, 336 U.S. 106 (1949). 
impact. ${ }^{225}$ But there is no history of using bus or train fares as a way to designate nonwhites as inferior, ${ }^{226}$ and, most importantly, we do not think of fare increases in racial terms.

The same would be true of an increase in the sales tax, the fee for obtaining a driver's license, or the cost of a building permit. These are all cases where the impact on blacks in a particular instance may be greater than it is on whites. They are also cases where some stigma may attach to those who are excluded by the governmental action. But we are likely to think of the in-group and out-group in economic rather than racial terms. These actions do not contribute directly to the system of beliefs that labels blacks as inferior. ${ }^{227}$ Where the culture as a whole does not think of an action in racial terms, it is also unlikely that unconscious attitudes about race influenced the governmental decisionmaker.

The easy cases at this end of the spectrum are precisely the kind of cases to which Justice White alluded in Davis when he warned that a discriminatory impact standard might invalidate "a whole range of tax, welfare, public service, regulatory, and licensing statutes that may be more burdensome to the poor and to the average black than to the more affluent white." 228 The cultural meaning test, by distinguishing racially stigmatizing statutes from those that only stigmatize indirectly through their economic impact, would go a long way toward obviating Justice White's concern.

\section{Some Harder Cases}

Where there is less agreement about the social meaning of allegedly discriminatory governmental action, the application of the cultural meaning test will, of course, be more difficult. But the process of applying the test and its underlying rationale will be the same. By looking at

225. "Disparate impact" is a term of art which the Supreme Court has adopted in decisions interpreting Title VII of the 1964 Civil Rights Act, 42 U.S.C. $\$ 2000$ e (1982). Disparate impact cases "involve employment practices that are facially neutral . . . but that in fact fall more harshly on one group than another and cannot be justified by business necessity." International Bhd. of Teamsters v. United States, 431 U.S. 324, 336 n.15 (1977).

226. Cf. Harper v. Virginia Bd. of Elections, 383 U.S. 663 (1966) (declaring poll tax unconstitutional). Because of the historical use of the poll tax as a racially exclusionary device and because of the systematic exclusion of blacks from the judicial system in certain areas, increasing the fees necessary to gain access to the political process or judicial system may have racial meaning.

227. There is, of course, an indirect route whereby the disparate impact confirms the belief in racial inferiority, but I am attempting to limit the merging of economic and racial discrimination by distinguishing direct racial insult from the indirect stigma of economic discrimination.

228. Davis, 426 U.S. at 248; see also Jefferson v. Hackney, 406 U.S. 535, 549 (1972). For a discussion suggesting that disproportionate impact analysis might invalidate tests and qualifications for voting, draft deferment, public employment, jury service, and other governmentconferred benefits as well as sales taxes, bail schedules, bridge tolls, license fees, and other government-imposed charges, see Goodman, supra note 10, at 300; see also Demsetz, Minorities in the Market Place, 43 N.C.L. Rev. 271 (1965); Silverman, Equal Protection, Economic Legislation, and Racial Discrimination, 25 VANd. L. Rev. 1183 (1972). 
how the test might be applied to several more difficult cases, this section explores in greater detail how a court might gather and interpret evidence of cultural meaning.

\section{Arlington Heights. ${ }^{229}$}

In Arlington Heights, a nonprofit development corporation obtained a purchase option on fifteen acres of land on which it planned to develop a federally subsidized, racially integrated, low and moderate income townhouse project. The proposed site of the project was in the Village of Arlington Heights, a Chicago suburb of over 64,000 residents of whom, as of 1970 , twenty-seven were black. ${ }^{230}$ Because the site was zoned for single family dwellings, the development corporation petitioned the village to rezone the property for multiple family use. When the village board of trustees, following the recommendation of the planning commission, denied the rezoning request, the developer and three blacks who were prospective tenants of the proposed project filed suit in federal district court.

Several kinds of evidence would be available to demonstrate that denying the zoning variance in these circumstances has a cultural meaning that demeans blacks. Initially, plaintiffs could present evidence of the historical and contemporaneous meaning of residential segregation in the culture as a whole. This would include the history of statutorily mandated housing segregation ${ }^{231}$ as well as the use of restrictive covenants among private parties that aim to prevent blacks from purchasing property in white neighborhoods. ${ }^{232}$ Studies of racially segregated housing patterns throughout the United States and in the areas surrounding Arlington Heights ${ }^{233}$ as well as data and attitudi(1977).

229. Village of Arlington Heights v. Metropolitan Hous. Dev. Corp., 429 U.S. 252

230. Id. at 255.

231. See Harmon v. Tyler, 273 U.S. 668 (1927); Buchanan v. Warley, 245 U.S. 60 (1917); see also L. Litwack, North of Slavery: The Negro in the Free States 1790-1860, at 168-70 (1961); D. McKay, Housing aNd RaCE IN INDUSTRIal Society 45-77 (1977).

Note that the Supreme Court in Arlington Heights, listed "historical background of the decision" as one of the evidentiary factors appropriate to a determination of the presence or absence of discriminatory purpose, but the Court then went on to limit its historical inquiry to the immediate legislative and administrative history of the decision, omitting any mention of broader historical context. Arlington Heights, 429 U.S. at 267. The historical use of a cultural symbol is even more directly related to a determination of contemporary social meaning and unconscious motivation.

232. See Barrows v. Jackson, 346 U.S. 249 (1953); Hurd y. Hodge, 334 U.S. 24 (1948); Shelley v. Kraemer, 334 U.S. 1 (1948); see also C. ABraMs, ForbidDEN Neighbors 224-25 (1955) (describing a seemingly inexhaustible series of devices to protect the exclusiveness of white residential areas).

233. See generally J. Kushner, Apartheid in America (1980); Segregation in ResidenTIAL AREAS (A. Hawley \& V. Rock eds. 1973); Farley, Residential Segregation and its Implications for School Integration, 39 Law \& Contemp. ProBs. 164 (1975); Grodzins, Metropolitan Segregation, ScI. AM., Oct. 1957, at 33; U.S. Housing Segregated and Unequal, Report Says, S.F. Examiner, Feb. 11,1985 , at A6, col. 1 . 
nal surveys on residential segregation and "white flight"234 would also be relevant. Such studies have indicated that collective and individual tolerances for black neighbors vary from community to community. ${ }^{235}$ While they ascribe the intolerance to different causes, ${ }^{236}$ they agree substantially on the prominence of race in the minds of both those who flee and those who stay. They also note whites' continuing aversion to housing integration. ${ }^{237}$

The body of evidence that documents our culture's frequent attachment of racial meaning to the very existence of segregated housing is extensive and should be more than sufficient to establish the cultural meaning of the Arlington Heights city officials' action. We have rarely come to live in racially segregated enclaves as the result of happenstance or out of mutual choice. We live in segregated neighborhoods because whites have believed that living with or close to blacks lowers their own status. Where one lives is an important index of one's status in our culture, and to live in proximity to those who are looked down upon is to be looked down upon oneself. ${ }^{238}$

This evidence of what racially segregated housing patterns mean in our culture would not be the only evidence available to the court. There is also direct evidence of the meaning Arlington Heights residents attached to the city's decision denying the zoning variance. The planning commission considered the proposal at a series of three public meetings which drew large crowds. Many of those in attendance were quite vocal and demonstrative in their opposition to the project, although some spoke in support of rezoning. But both opponents and supporters referred to the "social issue"-the desirability or undesirability of introducing low and moderate income housing that would probably be racially integrated into this area of Arlington Heights. ${ }^{239}$

The Supreme Court in Arlington Heights noted this evidence and observed that some opponents of the housing project "might have been

234. For a discussion of several studies and opinion polls indicating substantial white resistance to housing integration and documenting the phenomenon of "white flight," see Ackerman, Integration for Subsidized Housing and the Question of Racial Occupancy Controls, 26 STAN. L. REv. 245, 253-54 (1974).

235. Studies of "white flight" have explored both the racial transition of neighborhoods directly attributable to residential integration and the movement of whites to the suburbs as a result of school desegregation. The former phenomenon is known as the "tipping principle," according to which white families will leave a neighborhood when the black percentage of the population exceeds a certain point, usually somewhere between $30 \%$ and $50 \%$. See id at 25155.

236. See id. at 251-66.

237. See Pettigrew, Attitudes on Race and Housing, in Segregation in Residential Areas, supra note 233, at 21-29; see also Fremger, Housing Discrimination: A Problem that Won't Go Away, Wash. Post, July 17, 1982, at E1, col. 1 .

238. See D. BeLL, supra note 21 , at 475 ("Housing is not only shelter, it represents status, and the general view is that blacks residing in a neighborhood will lower the status and hence the value of property in the area."); see also K. CLARK, DARK GHETTO $32-33$ (1965).

239. Arlington Heights, 429 U.S. at 257-58. 
motivated by opposition to minority groups."240 But the Court went on to affirm the trial court's holding that the evidence "[did] not warrant the conclusion that this [racial opposition] motivated the defendants." 241 If, however, this same evidence is considered for the purpose of determining the cultural meaning of the city's action, it is far more probative. Even the court's terse description of the public meetings makes clear that race was prominent in the minds of both opponents and proponents of the project. The trial court, in its search for discriminatory purpose, found that the obvious prominence of the race issue did not warrant a finding of racial motivation. ${ }^{242}$ But, if the court's inquiry had focused on the meaning this community attached to the decision to exclude the project, this evidence of heated debate on the question of race would necessarily carry a great deal more weight. ${ }^{243}$

A final source of evidence regarding the racial meaning of the city's action is the unreasonableness of the nonracial criteria upon which the zoning board relied. Single family residences constituted the dominant and preferred land use in the village; the board invoked a "buffer policy" that restricted multiple family residences to areas between single family zones and commercial or industrial zones as its reason for denying the rezoning request. ${ }^{244}$ But the proposed multiple family residences were not high-density apartments. The project would have consisted of twenty two-story buildings on fifteen acres of land, 60 percent of which would have remained open space; a screen of trees and shrubs would have separated the project from neighboring houses. ${ }^{245}$ There would have been little to distinguish the project from the tracts of small lot, single family dwellings in the area. Applying the "buffer policy" in this case, where none of the legitimate purposes underlying the policy existed, should cast some doubt on whether these "normal criteria" were applied for "normal"- that is, nonracial-reasons. ${ }^{246}$ Alternatively, it may indicate the decisionmakers' unconscious, stereotyped view of housing occupied by nonwhites: Their image of what the project would look like may have been influenced as much by their ex-

240. Id. at 269 .

241. Id. at 269.

242. Metropolitan Hous. Dev. Corp. v. Village of Arlington Heights, 373 F. Supp. 208, 211 (N.D. Ill. 1974), rev'd, 517 F.2d 409 (7th Cir. 1975), rev'd, 429 U.S. 252 (1977).

243. By asking whether race was a motivating factor, the Supreme Court discounted the evidence of racial bias with evidence of racially neutral intentions and normal procedures. Arlington Heights, 429 U.S. at 269, 270 n.21. But under a cultural meaning approach, such discounting would not be appropriate. Even if we accept the Court's conclusions that the decisionmakers ultimately based their decision on noninvidious factors, the tenor of the public meetings and the views expressed therein are strong evidence of how the community interpreted the decision and of the unconscious attitudes that were manifested by that decision.

244. Id. at 270-71.

245. Id. at 257-58. The Supreme Court found that no novel criteria had been applied to the project, but it did not consider the reasonableness of the application of the criteria that were used.

246. See Lotero, supra note 130 , at $376-77$. 
pectations about housing occupied by blacks as by the actual plan and drawings presented.

Our culture attaches racial meaning to residential segregation. When we see an all-white neighborhood in close proximity to an allblack one, we do not imagine that it is white because its inhabitants' forebears settled there generations ago or that blacks have chosen not to live there. ${ }^{247}$ Our initial thought is that it is white because nonwhites have been excluded. This cultural meaning is evidence that no one who is a part of this culture could have made a decision like that made in Arlington Heights without race on his mind, the effectiveness of our psychodynamic censors notwithstanding. Furthermore, this cultural meaning is considerably more relevant to the stigmatizing injury that blacks suffer than is the conscious intent of the decisionmakers. If our culture interprets a decision to exclude blacks from a neighborhood as evidence of blacks' continued untouchability, that decision becomes part of the system of mutually reinforcing racial stigma that denies blacks the status of full humanity. ${ }^{248}$

\section{Washington v. Davis. ${ }^{249}$}

Davis presents a more difficult case than Arlington Heights. Two unsuccessful black candidates for positions in the District of Columbia Metropolitan Police Department alleged that some of the Department's hiring practices-particularly "Test 21," a written test that blacks failed at a rate roughly four times that of whites ${ }^{250}$ - discriminated against blacks and violated the guarantee of equal protection implicit in the fifth amendment's due process clause. "Test 21 ," which was used throughout the federal civil service, was designed to test verbal ability, vocabulary, reading, and comprehension. While the Court found that the test was a useful indicator of success in police training school, there was no proof that either the test scores or the school's examination scores predicted job performance or measured success in job-related training. ${ }^{251}$

What evidence might the plaintiffs have presented to establish that the government's action in this case had racial meaning? Unlike segregated housing, we do not ordinarily associate the use of civil service exams with race. But an action that has no racial meaning in one context may have significant racial meaning in another. We have seen that human behavior must be examined in context, as it may well derive its meaning from the specific historical and cultural milieu in which it takes

247. There are many places where both of these possibilities are likely to be true, including North Dakota, Minnesota, and Idaho. But these are not the locations where housing discrimination cases have arisen.

248. See note 156 supra and accompanying text.

249. 426 U.S. 229 (1976).

250. Id. at 237.

251. Id. at 256-70 (Brennan, J., dissenting). 
place. Despite the race-neutral origins of civil service exams as a generic entity, one has an intuitive sense that their use in this case has racial connotations-that this case is more like the Memphis wall than it is like an increased bus fare or a regressive tax. It is important to pay heed to one's intuitions at this juncture. One individual's gut feeling is hardly conclusive evidence of cultural meaning, but such feelings often derive from feelings that are more widely shared, and they may well indicate that more substantial testimony is available.

At this point, it is helpful to consider the setting in which "Test 21" was employed. Can one identify the contextual elements that have attracted the attention of our intuition? Are there elements not present in other civil service cases, elements that speak in terms of race? The most obvious racial element is the exam's racially disproportionate impact. One can argue that the government's action racially stigmatizes because blacks fail the exam in larger numbers than whites. But not every case of racially disparate impact has racial meaning. An increased bus fare may burden a larger percentage of blacks than whites, but we do not think of the fare increase as a direct stigmatization of blacks. It does not convey a message of racial inferiority. ${ }^{252}$ Thus, if the governmental action in Davis conveys a racial message, it must derive that meaning from something other than, or in addition to, its racial impact. Like the traffic barrier in Memphis $v$. Greene, there must be something in the particulars of its historical and cultural context that causes us to interpret this action-at least intuitively-in racial terms.

I suggest that there are two such elements. The first involves the nature of the work or activity from which blacks have been excluded: the job of police officer in a predominantly but not entirely black community. The second relates to the reason given for their exclusion: that they failed to demonstrate sufficient proficiency in verbal and written language skills.

It is significant that the challenged action in Davis excluded blacks from working as police officers and not as mail carriers or bus drivers. The occupation of police officer has symbolic meaning within our culture. Police officers represent the law as well as enforce it. They are armed and have discretionary authority to use violence. They are charged with protecting the lives and property of some individuals within society and controlling the violent and unlawful behavior of others. If history-the accumulated meaningful behavior of our culture-has taught us to attach significance to race in considering these elements of the job of police officer-authority, control, protection, and sanctioned violence-then an action that determines the racial composition of a police force also has racial meaning.

Furthermore, throughout American history police forces have had a different relationship to black communities than to white communities.

252. See notes $225-228$ supra and accompanying text. 
In white communities, the police officer is viewed as a public servant. His job is to protect the lives and property of those in the community where he works. But the job of the law enforcement officer in black communities has been to control the communities' inhabitants and to protect the lives and property of whites who perceive blacks as the primary potential source of violence and crime.

For blacks, those entrusted with law enforcement and the firepower that gives them authority have always been servants of the white men in power who exploit blacks economically and demean them socially. ${ }^{253}$ Slaves were forbidden to bear arms ${ }^{254}$ and a white police force of overseers and sheriffs' posses enforced the master's law. ${ }^{255}$ With the abolition of slavery, the use of organized, socially sanctioned violence against blacks increased, and the authority of the sheriff's office was often indistinguishable from that of the Ku Klux Klan. ${ }^{256}$ As recently as 1967 , there were nearly a dozen major American cities where blacks accounted for over 25 percent of the population that were patrolled by police forces with only a token minority representation. ${ }^{257}$ It is not surprising that many black communities continue to view the police as an occupying army. 258

The fact that police officers are authority figures to white as well as black citizens is also significant in determining the cultural meaning of

\section{3.}

[T] here is no "American dilemma" because black people in this country form a colony, and it is not in the interest of the colonial power to liberate them. Black people are legal citizens of the United States with, for the most part, the same legal rights as other citizens. Yet they stand as colonial subjects in relation to the white society. Thus institutional racism has another name: colonialism ....

The black community perceives the "white power structure" in very concrete terms. The man in the ghetto sees his white landlord come only to collect exorbitant rents and fail to make necessary repairs, while both know that the white-dominated city building inspection department will wink at violations or impose only slight fines. The man in the ghetto sees the white policeman on the corner brutally manhandle a black drunkard in a doorway, and at the same time accept a pay-off from one of the agents of the white-controlled rackets ....

He is not about to listen to intellectual discourses on the pluralistic and fragmented nature of political power. He is faced with a "white power structure" as monolithic as Europe's colonial offices have been to African and Asian colonies.

S. Carmichael \& C. Hamilton, Black Power: The Polmtics of Liberation in America 5-10 (1967); see also F. FANON, THE WRETCHed of THE EARTH 38 (1963) ("The colonial world is a world cut in two. The dividing line, the frontiers are shown by barracks and police stations. In the colonies it is the policeman and the soldier who are the official, instituted go-betweens, the spokesmen of the settler and his rule of oppression."); Delgado, "Rotten Social Background": Should the Criminal Law Recognize a Defense of Severe Environmental Deprivation?, 3 L. \& INEQUALITY 9, 29-30 (1985).

254. See A. Higgingotham, supra note 21, at 39, 40, 76, 117, 131-32, 173, 184.

255. See L. BENNETT, supra note 21 , at $91,94-95$; J. FranKLIN, supra note 21 , at 135-36, 138-39.

256. Cf. H. Zinn, A People's History of The United States 198-99 (1980) (Southern whites used power to organize the Ku Klux Klan and other terrorist groups).

257. Table A: Nonwhite Personnel in Selected Police Departments, in REPORT OF the National Advisory Commission on Civil Disorders 169 (1968).

258. See note 253 supra. 
excluding large numbers of blacks from the D.C. police force. To the extent that our culture attaches specific meaning to the assignment of racial groups to certain occupational and hierarchical roles, behavior that maintains those role assignments will have racial meaning. For example, whites are accustomed to seeing blacks as servants performing menial tasks. Thus, whites are generally neither surprised nor threatened when they see black porters, maids, and janitors. This is not simply a reflection of the fact that many blacks have performed these jobs. It is also indicative of a historical and culturally ingrained system of beliefs that leads us to think of blacks as suited to these jobs, to associate the jobs with blacks.

By contrast, whites are not accustomed to seeing blacks in positions of authority or power. Black managers, black professors, and black doctors are confronted with reactions ranging from disbelief to resistance to concern about their competence. The historical exclusion of blacks from these jobs has been rationalized by a belief in their unsuitability for these roles. What is at issue here is not just occupational stereotypes born out of habit. These stereotypes manifest a larger and more complex ideology that has legitimized the white-over-black authority relationship. Stereotypes are cultural symbols. They constitute our contemporary interpretation of past and present meaningful behavior.

The argument in defense of all-male police forces provides a useful analogue for understanding our less readily apparent attitudes about authority and race. In suits alleging discrimination against women in the selection of patrol officers, police department defendants have argued that women would not make good officers because the job requires an individual who can command respect from the man on the street. Men, they have argued, would not take orders from women, and, therefore, women would be less effective patrol persons. ${ }^{259}$ In other words, the departments' discriminatory hiring practices have been defended as a necessary adaptation to the sexist beliefs and practices of the culture. ${ }^{260}$

Whites would be less likely to verbalize the same argument regarding blacks, but the fact remains that many individuals in our culture continue to resist and resent taking orders from blacks. ${ }^{261}$ If the court were convinced that the absence or presence of substantial numbers of black police officers on the D.C. force would be interpreted as the maintenance or disestablishment of culturally instilled beliefs about the

259. See C. Milton, Women in Policing 24-26 (1972).

260. Note that similar arguments are made by law firms respecting their clients. Some firms have sought to justify their failure to hire minorities and women by arguing that they must be sensitive to the preferences of their clients in selecting new associates and evaluating firm members for partnership.

261. See J. Farber, The Student as Nigger (1970); E. Goffman, Asylums (1961); W. Grier \& P. Cobbs, Black Rage (1968); R. Sennett, Authority (1982). 
need to control blacks and the appropriate roles for blacks and whites in authority relationships, then the Civil Service Commission's decision to rely on "Test 21 " would have racial meaning.

There is another reason why a significant segment of the culture is likely to view the exclusionary impact of "Test 21 " in racially stigmatizing terms. "Test 21 " was primarily a test of verbal and written skills. The Civil Service Commission justified its use of the test by noting its desire to upgrade the communication skills of the city's police officers. ${ }^{262}$ Our society has increasingly sought to measure intelligence through the use of written tests, and we have come to believe that performance on such tests accurately reflects the whole of our intelligence. 263 Thus, most people are likely to think of those who performed poorly on "Test 21 " not simply as lacking in communication skills but as unintelligent. The average person is likely to see the city's use of the test as an admirable and reasonable attempt to insure that the city has smart police officers. If larger numbers of blacks than whites fail the test, this will be seen as proof that blacks are not smart enough for the job.

But evidence of cultural meaning must include more than disproportionate impact. Some whites also performed poorly on the test. Observers of the test's results would not necessarily conclude that, because blacks performed less well on this test, they are intellectually inferior as a group. They might think instead that the blacks who took this test just happened to be a less intelligent group, that less well-educated people performed less well on the test and the blacks who took this test had not on the whole received as good an education as the whites, or that poor people are less intelligent and blacks had done less well because a higher percentage of them were poor.

The cultural meaning test would require the plaintiffs to produce evidence that a substantial part of the population will interpret the disproportionate results of "Test 21 " not as the product of random selection or the differential educational background or socioeconomic status of the test takers but as testimony to the inherent intellectual abilities of the racial groups to which the test takers belong. In other words, the government's use of the test has racial meaning if our culture has taught us to believe that blacks that fail the test have done so because they are black.

This is precisely how most Americans will interpret the events in Davis. Throughout American history, a cultural myth that describes blacks as an inherently inferior race has justified their economic and social subjugation. At first, the myth found verification in religious

262. Davis, 426 U.S. at 246.

263. See Delgado, Bradley, Burkenroad, Chavez, Doering, Lardiere, Reeves, Smith \& Windhauser, Can Science Be Inopportune? Constitutional Validity of Governmental Restrictions on RaceIQ Research, 31 UCLA L. REv. 128 (1983) [hereinafter Race-IQ Research]. 
doctrine. ${ }^{264}$ By the mid-nineteenth century, the dogma of biblical scripture and verse was supplemented by the pseudoscience of biologists and social scientists who found fodder for the myth in craniometry, ${ }^{265}$ eugenics, and cultural anthropology. ${ }^{266}$ With the introduction of the I.Q. test in the early twentieth century, the psychometricians assumed primary authorship of this Homeric tale of God and nature's differential distribution of intellectual talent among the races. ${ }^{267}$ They provided the theory and numbers to prove the veracity of the myth, and the people's bards-the press, popular literature, and the theatertransformed the racism of pseudoscience into a folklore that shaped the nation's consciousness. ${ }^{268}$

During the last fifty years, the scientific community has done much to debunk both the data and theory of pseudoscientific racism. ${ }^{269}$ The use of intelligence tests to prove intergroup differences declined in the 1930 s when more thorough analyses of their findings indicated that discrepancies in education and environment explained the racial differentiations in test scores. But following the Supreme Court's decision ordering an end to school segregation, there was a resurgence in the use of I.Q. tests by educators and politicians who sought to avoid implementing Brown.270 In 1969, Arthur Jensen's landmark article on race and I.Q. in the Harvard Educational Review gave racial eugenics a new legitimacy. ${ }^{271}$ While his ideas came under immediate attack from both the scientific and political communities, ${ }^{272}$ the serious attention given them by academicians and politicians is evidence that the myth of racial inferiority is not dead. ${ }^{273}$

Even where notions of genetic inferiority have been rejected, more sophisticated theories of "cultural inferiority" have emerged to take their place. Their proponents attribute racial disparities in academic achievement and intellectual skills to an intellectually debilitating culture of poverty in which large numbers of blacks have grown up. ${ }^{274}$

264. One popular nineteenth century belief traced blacks' inferior social position to their imaginary descent from certain biblical ancestors. See, e.g., J. BLum, Pseudoscience AND MENTAl ABILITy 99 (1978); T. GossetT, RACE: The History OF AN IDEA IN AMERICA 5, 62-63 (1963).

265. See S. Gould, The Mismeasure of Man 30-72 (1981).

266. See J. BLUM, supra note 264, at 25-69.

267. See id. at 99-103; see also S. Gould, supra note 265, at 174-234.

268. See R. KLUGER, supra note 204 , at $84-86$.

269. See Race-IQ Research, supra note 263, at 139, 209-11; note 272 infra.

270. See, e.g., Lemon v. Bossier Parish School Bd., 444 F.2d 1400 (5th Cir. 1971); United States v. Sunflower County School Dist., 430 F.2d 839 (5th Cir. 1970); Singleton v. Jackson Mun. Separate School Dist., 419 F.2d 1211 (5th Cir. 1970) (en banc); Smuck v. Hobson, 408 F.2d 175 (D.C. Cir. 1969) (en banc), aff' $g$ Hobson v. Hansen, 44 F.R.D. 18 (D.D.C. 1968).

271. Jensen, How Much Can We Boost I.Q. and Scholastic Achievement, 39 HARv. Educ. REv. 1 (1969); see also A. Jensen, Bias in Mental Testing (1980).

272. See S. Gould, supra note 265, at 127, 317-20; L. Kamin, The Science and Polmtics OF IQ (1974); E. SHARP, The I.Q. CulT (1972).

273. See J. Dreyfuss \& C. Lawrence, The Bakke Case: The Politics of Inequality 134-35 (1979); see also Race-IQ Research, supra note 263, at 138-39, 209-11.

274. For discussion and critique of this view, see K. CLARK, supra note 238; E. LEACOCK, 
But it has become increasingly popular to argue that this pathological culture is not the result of societal discrimination. Instead, the existence of the culture of poverty is attributed to some unspecified inadequacy in blacks themselves. ${ }^{275}$ Recent polls of racial attitudes indicate that "most whites do not believe that racial discrimination is the principal cause of black inequality." 276 But if not discrimination, then what? For many whites, the explanation lies in the inherent inferiority of blacks. Few will express this belief openly. It is no longer consistent with American ideology to speak in terms of inherent racial traits. But the myth of racial inferiority remains embedded in the fabric of our culture.

Plaintiffs trying Davis under the test proposed in this article would present evidence detailing both the history and the contemporary manifestations of this myth. They would seek to convince the court that most people in our culture believe that the average white person is inherently smarter than the average black person and that whites will interpret the racially selective impact of "Test 21 " as a confirmation of that belief. If the culture gives the governmental action this kind of racial meaning, the action constitutes a direct racial stigmatization. Like the segregated beach and the Memphis wall, it conveys a message that has its origins in a pervasive and mutually reinforcing pattern of racially stigmatizing actions, and it adds one more stigmatizing action to that pattern. Presumably, the decisionmakers who chose to use "Test 21 " were aware of that message and were influenced by it, whether consciously or unconsciously.

Ely's process defect analysis helps explain why proof that governmental action will be interpreted in racial terms should lead a court to closely scrutinize that action. In selecting "Test 21 " to screen police applicants, the Civil Service Commission weighed a number of benefits and costs. The fact that the test helps select candidates with good communication skills is, presumably, a benefit. Yet the test may also exclude many of those who are best able to establish rapport with the residents of the communities in which they work and best able to inspire their trust and confidence. The test may save time and money by making it unnecessary to offer additional training in communication skills in the police academy. But it may also create costs by selecting those candidates who will most need sensitivity training and community relations workshops. Likewise, the less tangible benefits of maintaining a work force with which the predominantly white residents of Capitol Hill, visiting tourists, and upper level bureaucrats will be comfortable must be weighed against the costs of failing to create more employment

The Culture of Poverty: A Critique (1971); C. Valentine, Culture and Poverty: CriTIQUE AND CounTER-Proposals (1968); see also Baratz \& Baratz, Early Childhood Intervention: The Social Science Base of Institutional Racism, 40 Harv. Educ. Rev. 29 (1970).

275. See W. Ryan, Blaming the Victim (rev. ed. 1971).

276. J. Dreyfuss \& C. Lawrence, supra note 273 , at $142-44$. 
opportunities for the city's predominantly nonwhite, low income residents.

This is but a small sampling of the kind of political prioritizing that must take place when any decision is made. Much of this weighing of costs and benefits is implicit. Some considerations receive the lowest priority because they are never considered. The Court in Davis tells us that the government's purpose in adopting "Test 21" was to "modestly upgrade the communicative abilities of its employees."277 We do not know whether this benefit was considered so important that it outweighed all of the costs listed above, or whether those costs were never even considered. An unconscious belief in the intellectual inferiority of blacks may have led the decisionmakers to put more stock in the test's ability to measure relevant skills than was justified. An inarticulate discomfort when confronted by blacks in positions of authority may not have led a commissioner to intentionally exclude blacks from the force, but it may have caused him to respond to the test's potential for discriminatory impact with relief rather than concern. His insensitivity to the importance the city's blacks would attach to more black faces on the beat might mean that this consideration was never even weighed in the balance.

These are the very "racially selective sympath[ies] and indifference[s]"278 that create misapprehensions of process defects. These sympathies overestimate the validity of generalizations that are self-flattering - for example, that written tests accurately measure an important kind of intelligence. And they undervalue the benefits of alternativesfor example, a test that measures judgment in real life situations or empathy with community residents-that would enhance the fortunes of others.

\section{Government subsidies to the poor.}

Proving racial meaning under the cultural meaning test will be most difficult in cases like Dandridge v. Williams, ${ }^{279}$ Jefferson $v$. Hackney, ${ }^{280}$ and Harris $v$. McCrae. ${ }^{281}$ Each of these cases challenged a governmental decision to limit subsidies to the poor for such basic human needs as food, clothing, shelter, and medical services. None of them claimed intentional racial discrimination. And in all three cases the Court, having found that the challenged statute concerned economics and social welfare, upheld it under the rational relationship test. The Court's position in each case was that neither a classification based upon differential wealth nor the fact that the classification burdened a basic need was a basis for applying strict scrutiny.

277. Davis, 426 U.S. at 246.

278. Brest, supra note 7 , at 14 .

279. 397 U.S. 471 (1970).

280. 406 U.S. 535 (1972).

281. 448 U.S. 297 (1980). 
If one adopts the Court's reasoning, these cases are prototypical examples of the kind of neutral tax and welfare laws that Justice White sought to secure from invalidation in Davis. ${ }^{282}$ In all three cases, the legislative decision not to allocate resources produced a racially disparate impact. Dandridge and Jefferson concerned laws that imposed an upper limit on the amount a family could receive from Aid to Families with Dependent Children ("AFDC"), thus funding those recipients at a lower percentage of acknowledged need than recipients in such other welfare categories as the aged and disabled. ${ }^{283} \mathrm{McCrae}$ involved the exclusion of certain abortions from coverage under a federal medicaid act. ${ }^{284}$ Blacks and Mexican-Americans were disproportionately represented in each of the disfavored groups, but without proof of racial animus, the Court considered their disparate burden irrelevant to the statutes' constitutionality. ${ }^{285}$

If these cases were decided under the cultural meaning test, the Court would ask whether most people would interpret the decisions to disfavor AFDC recipients and to not fund abortions as having something to do with race. Would they view the decisions in racial terms, like the decision to barricade the streets of Memphis or to close the pools of Jackson, Mississippi?286 Or would they view the decisions in racially neutral terms, like a decision not to fund the MX missile or to increase farm subsidies?

In Dandridge and Jefferson, plaintiffs would have to establish that a significant segment of the population perceives a decision to limit the funds available to AFDC recipients as a racial statement. They might present data on how survey respondents describe a typical AFDC recipient. Do most people think of all AFDC recipients as black, Puerto Rican, or Mexican-American? Do these perceptions reflect statistical reality, or are they based on generalizations? Do the survey respondents hold pejorative beliefs about AFDC recipients that coincide with prevalent racial stereotypes?287 Do they perceive the government's rationales-which include providing incentives for family planning, encouraging gainful employment, and avoiding discrimination between welfare families and families of the working poor ${ }^{288}$-in racial terms? Is there historical or current evidence from the social sciences that we

282. Davis, 426 U.S. at 248 \& n. 14 .

283. Jefferson, 406 U.S. at 537, 547; Dandridge, 397 U.S. at $484-85$ \& n.17.

284. McCrae, 448 U.S. at 326.

285. See notes 283-284 supra.

286. See City of Memphis v. Greene, 451 U.S. 100 (1981); Palmer v. Thompson, 403 U.S. 217 (1971).

287. I am not aware of any existing research exploring the question of whether people tend to think of AFDC recipients in racial terms. My intuitive sense is that there is a widely shared inaccurate perception that most AFDC recipients are black. For a discussion of pejorative attitudes toward AFDC recipients, see Rainwater, Stigma in Income Tested Programs, in INcome Tested Transfer Programs 19 (I. Garfinkel ed. 1982); see also B. Leyser, A. Blong \& J. Riggs, Beyond the Myths: The families Helped by the AFDC Program (2d ed. 1985).

288. Dandridge, 397 U.S. at $483-84$. 
believe nonwhites are more likely to burden society with unsupported children or more likely to avoid available employment in order to stay on the dole?289

It would also be useful for the Court to examine contemporaneous policy discussions within the academic and political communities about the efficacy of welfare programs as well as media coverage of the debate over welfare legislation. Evidence that the disutility of increased welfare was presented in racial terms would be considered not to prove that the legislature sought to demean or punish blacks but to show that many people will interpret the decision to limit AFDC funding as a demeaning racial statement. ${ }^{290}$

Plaintiffs in McCrae would face an even more difficult task: They would have to establish a relationship between the strength of public sentiment against abortion-the perception that government-funded abortions condone and encourage promiscuity and irresponsible sexand the belief that such behavior is more prevalent among certain racial groups than others. ${ }^{291}$ This argument will be especially difficult because of the deep feelings surrounding this issue that are unrelated to race. In other words, the presence of strong cultural meaning unrelated to race-in this case, meaning related to religious beliefs about the existence and sanctity of prenatal human life-will tend to weaken the argument that the culture will think of the action in racial terms.

It has not been my purpose here to prove the cases that plaintiffs might have made in Arlington Heights, Davis, Dandridge, Jefferson, and McCrae. Instead, I have tried to show how the proof which the cultural meaning test requires would differ from that required under the Davis doctrine and to demonstrate how the cultural meaning test more directly addresses the relevant constitutional issues of stigma and process defect.

\section{E. Applying the Cultural Meaning Test}

One can anticipate several additional difficulties regarding the test's application. I think that none of them are insurmountable. And while their resolution is not within the scope of this article, I will discuss each

\section{See notes 274-275 supra.}

290. For example, plaintiffs might point to the widespread impact of Daniel P. Moynihan's much-publicized report on "The Negro Family." See D. Moyninan, The Negro Family: ThE CASE FOR NATIONAL ACTION (1965). This report connects the increase in the AFDC rolls to what Moynihan terms "the steady disintegration of the Negro family structure." Id. at 14. Moynihan argues that increasing welfare subsidies only fosters this disintegration; he concludes that "the present tangle of pathology [in the black family] is capable of perpetuating itself without assistance from the white world." Id. at 47.

291. See notes 274-275 supra; see also Payne, Ethnic Pilfering in American Society, S.F. Chronicle, June 11, 1986, at 48, col. 5 (citing a study which found that while white women are five times as likely as black women to abort their first pregnancy, black women "have been taking a disproportionately bad rap for their sexual behavior"). 
of them briefly in order to indicate the direction such resolution might take.

\section{When "bad" means "good": conflicting cultural meanings.}

An initial difficulty with applying the cultural meaning test arises from the fact that we are not a monolithic culture. There may be instances in which governmental action is given different meanings by two subcultures within the larger culture. For example, the court might find that blacks see the decision to fund AFDC recipients at lower levels than other need-categories in racial terms while whites do not, or the court may find that people in northern urban areas give racial meaning to restrictions on federally funded abortions while people in southern rural areas do not. ${ }^{292}$

The easiest solution to this problem is to acknowledge racial meaning for constitutional purposes only when the evidence indicates that the racial understanding will be widely shared within the predominant culture. ${ }^{293}$ This solution is better than the Davis/Arlington Heights intent test in that, at a minimum, it will correctly identify unconscious intent in cases like Memphis v. Greene or even Arlington Heights. ${ }^{294}$

292. This problem most commonly arises when a victimized group chooses to segregate itself. Does the presence of a black dormitory or a predominantly black university stigmatize blacks if the segregated institution reflects blacks' choice of cultural solidarity, political control, or educational quality over racial integration? See D. BELL, supra note 21, at 411-15.

293. I am not certain that this "easy solution" is entirely satisfactory. My thesis sees cultural meaning as a proxy for the unconscious motivation of the decisionmaker and, therefore, seems to require that the dominant group's interpretation be critical to any application of the test. But there may be occasions when the meaning of a governmental action within the subculture most immediately affected is the most probative evidence of that action's meaning in the dominant culture. A victimized group may be more sensitive to attitudes and values in the dominant culture than are individuals who have been fully integrated into that culture. For example, the anthropologist who observes another culture is likely to be more objective than if she were observing her own culture. De Toqueville's and Myrdal's examinations of American culture exemplify this phenomenon. Likewise, the minority subculture may well see the dominant culture more clearly than the dominant culture sees itself.

Brown provides precedent for this attention to the interpretation of subcultures. The Brown Court focused on the meaning that black children attached to laws requiring segregated schools. Brown is an easy case, in that the racial meaning of segregated schools was also readily apparent to members of the dominant culture. But in harder cases, it may be useful to give special consideration to the subculture's interpretation.

294. Several colleagues have raised concerns about applying the cultural meaning test in affirmative action cases. They wonder whether the test would allow conservative judges to find that programs designed to remedy past or ongoing racial discrimination have racial meaning and are, therefore, unconstitutional. This is a question that deserves more extensive discussion than it can be given here. A preliminary response is that most affirmative action cases arise in the context of "race conscious" remedies where the racial classification is apparent on the face of the statute. See, e.g., Fullilove v. Klutznick, 448 U.S. 448 (1980); Regents of the Univ. of Cal. v. Bakke, 438 U.S. 265 (1978). In such cases, the intent to classify on the basis of race is evident and is admitted by the defendants. The issue to be resolved by the cultural meaning test is, therefore, moot. The question before the Court in these cases is not whether the racial classification exists but whether it can be justified. Of course, the question of the cultural meaning or stigmatizing nature of the admitted racial classification remains an important question, particularly for Justice Brennan and those who joined his opinion in 
2. The blind interpreting for the blind: the problem of judicial bias.

A second difficulty with the cultural meaning test rests in the inevitable cultural biases of judges. Judges are not immune from our culture's racism, nor can they escape the psychological mechanisms that render us all, to some extent, unaware of our racist beliefs.

We must recognize, however, that this difficulty inheres in all judicial interpretation. ${ }^{295}$ The advantage of the cultural meaning test is that it makes the issue of culturally induced bias explicit. The judge who is hearing evidence regarding how our history and culture have influenced our racial beliefs is more likely to be made aware of his own heretofore unrecognized biases. Judges continue to come primarily from elite white backgrounds. ${ }^{296}$ They undoubtedly share the values and perceptions of that subculture, which may well be insensitive or even antagonistic toward the values, needs, and experiences of blacks and other minorities. The benefit of the cultural meaning test is that it confronts judges with this conflict and forces them to take responsibility for their own biases and preconceptions.

\section{3. "Media meaning": the problem of the self-fulfilling prophecy.}

A third difficulty in applying the cultural meaning test arises where the parties, particularly the plaintiffs, create a racial issue where there seemingly was none. How, for example, should a court treat a challenge to a state bar exam where the racial issues were not apparent until mass demonstrations or a media campaign attracted public attention to them? Again, the answer must be found in the sophistication of the interpretive process. Is the newfound awareness of the racial issue merely a result of media hype, or has the media campaign succeeded because it has touched a cultural nerve lying just below the surface of our consciousness?

Each of these potential problems indicates that the cultural meaning test will not create an easily recognizable bright line for judges to fol-

Bakke. See id. at 324 (Brennan, White, Marshall, and Blackmun, JJ., concurring in part and dissenting in part).

There are also some potential challenges to facially neutral affirmative action programs such as the "Harvard Plan" cited by Justice Powell in Bakke, id. at 316-17, where race may be a more or less apparent factor in the decisionmaking process. The problems of conflicting cultural meanings (do whites, but not blacks, perceive the program as stigmatizing?) and judicial bias, see notes 292 supra, 295-296 infra and accompanying texts, make these cases problematic, but the fact that the purposes are apparently remedial will not change the nature of the problems of interpretation. See notes 196-201 supra and accompanying text (discussing gender discrimination cases).

295. See notes 205,208 supra.

296.

Of 253 of Mr. Reagan's nominees to the Federal bench in his first five years, only

four were black, 11 Hispanic, one Asian, and 22 women. Almost all were affluent, with the majority each having a net worth of more than $\$ 400,000$. More than a fifth of the first-term appointees are millionaires.

Broff \& Aron, Judgeships Made Easy, N.Y. Times, Apr. 18, 1986, at A35, col. 1. 
low. The test's advantage lies not so much in its ease of application as in its ability to spotlight the source of injury in cases of racial discrimination: the unconscious racism that continues to pervade our culture and influence our decisionmaking.

\section{The Court's Competence: A Search for Neutral Principles}

The fourth skepticism concerning my thesis, to which this article alluded earlier, concerns the appropriate role for the courts in our constitutional system. It asks whether the judiciary, by applying the cultural meaning test, will be overstepping its rightful place in the constitutional framework and usurping the powers of those branches that represent the will of the people more directly.

This argument proceeds roughly as follows: When a majority of the people expresses its will through the actions of the legislative and executive branches, the judiciary should not interfere with those actions by requiring a heightened level of justification from the governmental actor unless those actions violate the Constitution's substantive or procedural principles. ${ }^{297}$ Only occasionally, however, will a constitutional principle be clearly stated and clearly violated. ${ }^{298}$ More often, the text of the Constitution articulates its values in broad terms such as "due process" and "equal protection" that are subject to a wide range of interpretations. Most Supreme Court jurisprudence consists of an effort to give some substantive content to these broad textual provisions. ${ }^{299}$

These efforts, however, are sensitive to the charge that, unless an interpretation is grounded in some "neutral principle" that rests on analysis and reasoning transcending the immediate result, it will amount to no more than a court imposing its own idiosyncratic values on the political majority. ${ }^{300}$ The objection to the cultural meaning test (1959).

297. See Wechsler, Toward Neutral Principles of Constitutional Law, 73 HaRv. L. REv. 1, 25

298. See, e.g., United States v. Johnson, 383 U.S. 169 (1966) (holding that Art. I, § 6 of the Constitution, which provides that "for any Speech or Debate in either House, [members of Congress] shall not be questioned in any other Place," barred the prosecution of a former member of the House of Representatives where his conviction required proof that the legislative act of making a speech before Congress was the result of bribery).

299. Unfortunately, this substantive content remains unarticulated. Karst and Horowitz have criticized the Court for focusing on the standard of review in due process and equal protection cases, thereby avoiding an explicit articulation of the substantive values that are implicit in their decisions to apply certain standards: "If its decisions are to be seen as principled, the Court must explain its principles as elaborations of substantive values in the Constitution. What is needed, then, is not further refinement of judicial methodology, but clear statement of the substantive meaning of equal protection." Karst \& Horowitz, supra note 14, at 24.

300. See Wechsler, supra note 297 , at 34 . The Court has been particularly sensitive to the charge that, by giving substance to the due process and equal protection clauses, it has revived the worst features of the Lochner era. For a catalogue of the numerous scholars who have voiced this criticism, see Wright, Professor Bickel, the Scholarly Tradition, and the Supreme Court, 84 HaRv. L. REv. 769, 770 (1971). 
is that to require heightened judicial scrutiny of actions found to have racially stigmatizing meaning entails a judicially imposed prioritization of the elimination of racial stigma over such other, popularly selected societal goods as quiet streets, neighborhood schools, and better educated police officers. In the absence of intentional racial discrimination-which clearly violates the antidiscrimination principle ${ }^{301}$-there is arguably no principled basis for requiring the majority to abandon its choice in favor of a choice that the court seeks to impose.

But there is such a principle: the principle of due process. Part II of this article reviewed Dean Ely's treatment of racial antagonism and the resulting misapprehension of costs, benefits, and overlapping interests as a process defect that violates the constitutional requirement that government treat individuals fairly. I argued that such a race-based process defect is no less injurious or reprehensible when it originates in the unconscious. ${ }^{302}$ The fact that governmental action has racial meaning within the culture is evidence that the decisionmaking process leading to that action was infected with the process defect Ely describes.

A second, more direct response to the argument that nonpurposeful racial stigmatization violates no neutral constitutional principle challenges the critic to articulate the premise upon which the argument for judicial restraint is based. What is the neutral principle that the equal protection clause embodies? And why should that principle encompass intentional racial stigmatization but not those cases identified by the cultural meaning test?

Some advocates of judicial restraint have ascribed to the equal protection clause the principle of rationality of means. ${ }^{303}$ They view this principle as neutral because, in its pure form, it only requires that the legislature achieve a certain level of efficiency in pursuing its goals; it does not question the goals themselves. The judicial role is to check whether legislative classifications have exceeded permissible levels of overinclusiveness or underinclusiveness. ${ }^{304}$ But it is also the court's role to articulate those permissible levels. Furthermore, the degree of overinclusiveness and underinclusiveness that the court will tolerate depends on the subject matter of the legislation. ${ }^{305}$ If the court finds that the legislation in question involves a racial classification, it will re-

301. See Brest, supra note 7, at 15; see also notes 307-309 infra and accompanying text.

302. See notes $126 \cdot 140$ supra and accompanying text.

303. See, e.g, Gunther, supra note 112, at 20-24 ("The [means-oriented] model of modest interventionism would have the courts do more than they have done for the last generation to assure rationality of means, without unduly impinging on legislative prerogatives regarding ends."); $c$. Freeman, supra note 3, at 1058 (criticizing the "means-oriented" approach which "regards the [equal protection] clause as nothing more than a judicial check on legislative mistakes .... In its pure form, the principle is perfectly abstract, concerned only with questions of neatness; inasmuch as it serves to check technique rather than goal, it is utterly valueneutral.").

304. See Tussman \& tenBroek, supra note 112 , at $344-53$ (discussing the principle of "reasonable classification").

305. Freeman has noted that "[s]ince any legislative generalization is likely to fall if sub- 
quire a substantially closer fit between means and goals than it would require from legislation concerning other matters, and it will almost invariably invalidate the legislation. ${ }^{306}$

This judicial choice to require a closer fit in cases involving racial classifications introduces yet another principle, one that disfavors racedependent conduct. ${ }^{307}$ But it is more difficult to describe this antidiscrimination principle as neutral, because it involves a substantive value choice that favors nonrace-dependent political choices over those that are race-dependent. Some scholars have argued that even without a clear textual or historical justification, the antidiscrimination principle gains legitimacy as a neutral principle from the fact that it rests on shared values. ${ }^{308}$ Moreover, to the extent that existing constitutional doctrine-particularly the Davis intent requirement-embraces the antidiscrimination principle as a neutral and, therefore, appropriate basis upon which to overrule a conflicting majoritarian value choice, it interprets that principle as only forbidding governmental decisions that selfconsciously aim to disadvantage a minority group selectively. ${ }^{309}$

But why should purposeful racial discrimination violate the antidiscrimination principle when unintentional racial stigmatization does not? Why is it appropriate for courts to impose upon the political branch a value choice that disfavors intentional racial stigmatization but not to impose a value choice that disfavors the stigmatization resulting from unconsciously held cultural beliefs and attitudes concerning race?

One answer might be that the neutral principle of judicial economy distinguishes the value choice disfavoring intentional racial discrimination from that disfavoring all racially stigmatizing governmental conduct; requiring extraordinary justification for all racially stigmatizing practices would simply involve the courts in too many cases. But this response is little more than a recapitulation of the parade of horribles Justice White set forth in Davis. ${ }^{310}$ I noted earlier that a test that looks

jected to strict scrutiny, the choice between [minimal and strict scrutiny] takes on a highly substantive content." Freeman, supra note 3, at 1059; see also Karst \& Horowitz, supra note 14. 306.

In sum, because of the significant risk that racial classifications established for ostensibly benign purposes can be misused, causing effects not unlike those created by invidious classifications, it is inappropriate to inquire only whether there is any conceivable basis that might sustain such a classification. Instead, to justify such a classification an important and articulated purpose for its use must be shown. In addition, any statute must be stricken that stigmatizes any group or singles out those least well represented in the political process to bear the brunt of a benign program. Thus, our review under the Fourteenth Amendment should be strict-not 'strict in theory and fatal in fact,' because it is stigma that causes fatality-but strict and searching nonetheless.

Regents of the Univ. of Cal. v. Bakke, 438 U.S. 265, 361-62 (1978); see Gunther, supra note 112 , at 8 .

307. See Brest, supra note 7, at 1-2; Freeman, supra note 3, at 1061.

308. Brest, supra note 7 , at 5; see notes $312-316$ infra and accompanying text.

309. Brest, supra note 7, at 26-39.

310. Washington v. Davis, 426 U.S. 229, 248 \& n.14 (1976). 
to racially stigmatizing meaning rather than to discriminatory effect will substantially shorten the length of that parade. ${ }^{311}$ Furthermore, to give judicial economy priority over the recognition of constitutional injury seems wrong. It is to make a value choice that is no different from the decision to deny that injury recognition altogether.

Paul Brest provides a more plausible reason for holding judicial activism appropriate in intentional discrimination cases but not in unintentional ones. He argues that the antidiscrimination principle gains its legitimacy from the fact that it rests on "fundamental moral values that are widely shared in our society." 312 If unintentional racial stigmatization does not violate the antidiscrimination principle, it can only be because, in contrast to intentional racial discrimination, most of us believe that the continuing presence of historical racial stigma does not violate fundamental moral principles.

Alan Freeman has described the approach that seeks to find neutral constitutional principles in shared values as a "new formalism" which disguises the fact that legal doctrine actually arises from "a continuing dialectic of struggle, characterized by value clashes that ... share no agreed-upon reference point." 313 The value clashes to which Freeman refers are those between, on the one hand, values that are defined from the vantage point of the perpetrators who are responsible for or benefit from discriminatory conditions and, on the other hand, values that are defined from the perspective of the victims who are burdened by the conditions we have come to associate with racial discrimination. ${ }^{314}$ Freeman's criticism of the shared values approach is that it fosters a false view of the world by acting as if the values it identifies are ones in which we all have an equal stake when, in fact, they are defined from the perspective of the perpetrators. ${ }^{315}$ One might better call these values "dominant values."

Of course, there is a sense in which the victims of discrimination share in the ideals of equality and racial justice, but the enterprise being considered here is that which gives meaning and substance to those ideals. And when one finds that intentional racial discrimination is morally reprehensible but that unconscious racial stigmatization is not, one has made a value choice that defines the "neutral" principle of antidiscrimination in terms that adopt one world view and reject another. The shared values approach, however, describes this choice as if no choice had been made, as if the dominant values were universal values. ${ }^{316}$

311. See notes $171,225-228$ supra and accompanying texts.

312. Brest, supra note 7 , at 5 .

313. Freeman, School Desegregation Law: Promise, Contradiction, Rationalization, in Skades of Brown: New Perspectives on School Desegregation 71, 72 (D. Bell ed. 1980).

314. Id. at 74 .

315. Id. at 74-75.

316. Id. at 74 . 
This criticism, that law and legal discourse serve a hegemonic function by legitimizing oppressive power relationships through false or misleading ideologies, is a central theme of legal academia's new left. ${ }^{317}$ In its most extreme form, the criticism characterizes any fundamental legal principle or shared value as an inevitably oppressive tool in the hands of those in power. A less extreme version only criticizes those approaches that claim the existence of some preexisting natural order or that seek to disguise the existence of conflicting world views by describing the dominant view as if it serves all persons equally well.

This less extreme critique might advance an approach between one that defines neutral principles by discovering sufficiently widely shared values and calling them "neutral" or "fundamental" to promote their popularity, and one that says there are no such things as shared values. This intermediate approach would acknowledge the existence and legitimacy of conflicting perspectives or world views while simultaneously promoting the full exposition and articulation of those perspectives. It would do so by denying any one view of established status and by encouraging face to face confrontation among conflicting views. The courts would continue to interpret constitutional values and principles, but instead of purporting to discover one true meaning in the text, it would be understood that there are many possible interpretations, that judges participate in the creation of meaning as well as in its discovery, and that our understanding of meaning may change. ${ }^{318}$

This is the approach described in Part III. ${ }^{319}$ Like the social scientist, the judge must recognize "that the values expressed in the laws are not culture-free and that our own best interpretation of them is rooted in culture." 320 John Denvir, in advocating a similar hermeneutical approach to constitutional interpretation, notes that this approach avoids the critiques of formalism and objectivism advanced against the positivist approach as well as the critique of nihilism against those on the left who, in seeking to demystify constitutional law, often seem to reject the validity of all judicial review. ${ }^{321}$ Denvir sees the chief benefit of this

317. Several critical commentators have described the process by which law has been made a vehicle for the transmission of ideological imagery that helps to preserve and legitimize. See note 30 supra and accompanying text; see also Crenshaw, Race, Reform, and Retrenchment: Transformation and Legitimation in Antidiscrimination Law (on file with author); Freeman, supra note 313; Kelman, Trashing, 36 STAN. L. REv. 293, 321-29 (1984); Kelman, Interpretive Construction in the Substantive Criminal Law, 33 STAN. L. REv. 591 (1981). (1986).

318. See Denvir, Justice Brennan, Justice Rehnquist, and Free Speech, 80 Nw. U.L. Rev. 285

319. See notes 188-190 supra and accompanying text.

320. Chevigny, Why the Continental Disputes are Important: A Comment on Hoy and Garet, $58 \mathrm{~S}$. CAL. L. REv. 199, 207-08 (1985).

321. Denvir writes that the hermeneutical approach:

avoids the critique of formalism by adopting a "looser and more contestable rationality" as its method and accommodates the critique of objectivism by acknowledging that there is no "necessary" order to social life and by integrating into legal discourse "the explicit controversy over the right and feasible structure of society." The social order is no longer a pre-existing given but a social creation of which law is 
approach to be its ability to make the normative element in law explicit: "Hermeneutics can help us develop a constitutional theory that is rationally persuasive without pretension to formalistic precision, and which openly admits that law is a part of politics."322

In short, it would not be a bad thing for judges to base constitutional decisions on their own sense of what values best reflect our cultural tradition, so long as the conflicting perspectives competing to define those values are made explicit. The search to define those values could then serve a clarifying, rather than a mystifying, role. It should be equally clear that the role of judges as interpreters differs from that of ordinary folks only by virtue of their responsibility to articulate their latest understanding of what we share. Thus, the normative debate would always continue.

The argument for this approach is particularly strong where issues of racial discrimination are concerned. While the positivist approach disguises value conflicts and legitimizes the status quo, to reject all judicial review would default to the product of the legislative process where the will of the majority legitimizes the results and where normative concerns are more easily dismissed as beside the point. Blacks and other historically stigmatized and excluded groups have no small stake in the promotion of an explicitly normative debate. While their version of shared values or fundamental principles-the victim's perspectivemay not hold sway at the moment, the courts can become a legitimate forum for the persuasive articulation of that version. And once the debate is made explicit, the hegemonic function of the law is diminished. This is not to say that the courts should become the exclusive or even the primary forum for normative debate, but rather that, by making the debate over fundamental principles explicitly political, one expands the arena for that debate.

If the jurisprudential task is to give sense to broad propositions of law-deriving that sense from an ongoing judicial interpretation of culturally created moral norms-then application of the proposed cultural meaning test is clearly within the courts' competence. The interpretation of the meaning of allegedly racially stigmatizing governmental action is but one step in a larger interpretive process that asks whether a fundamental moral principle has been violated. I have argued that it is appropriate for the courts to decide that the best interpretation of the constitutional principle of equality disfavors not just purposely discriminatory conduct but all conduct with racially stigmatizing meaning.

an important constituent; the judge no longer studies the text to discover meaning but participates in the invention of meaning. Nor is there only one possible meaning as the result of a judicial reading; hermeneutics admits to the existence of a multiplicity of possible interpretations.

Denvir, supra note 318, at 290 (quoting Unger, The Critical Legal Studies Movement, 96 Harv. L.

REv. 561, 578, $582(1981))$.

322. Id. at 292. 
Thus, deciding whether particular governmental conduct does or does not bear that meaning is a necessary and appropriate part of the courts' task.

\section{Conclusion}

Ultimately, the greatest stumbling block to any proposal to modify the intent requirement will not be its lack of jurisprudential efficacy but the perception among those who give substance to our jurisprudence that it will operate against their self-interest. Derrick Bell has noted that the interests of blacks in achieving racial equality have been accommodated only when they have converged with the interests of powerful whites: The legal establishment has not responded to civil rights claims that threaten the superior societal status of upper and middle class whites. $^{323}$ Alan Freeman has argued persuasively for the more radical proposition that antidiscrimination law has affirmatively advanced racism by promoting an ideology that justifies the continued economic subjugation of blacks. ${ }^{324}$ The intent requirement is a centerpiece in an ideology of equal opportunity that legitimizes the continued existence of racially and economically discriminatory conditions and rationalizes the superordinate status of privileged whites. ${ }^{325}$

The workings of the unconscious make this dissonance between efforts to achieve full civil rights for blacks and the self-interest of those who are most able to effect change even more difficult to overcome. The ideology of which Freeman speaks is more than a consciously wielded hegemonic tool of domination. ${ }^{326}$ It is also an unconscious defense mechanism against the guilt and anxiety of those who hold power and privilege through means and with motives that they cannot acknowledge. ${ }^{327}$ Racism continues to be aided and abetted by self-conscious bigots and well-meaning liberals alike.

I do not anticipate that either the Supreme Court or the academic establishment will rush to embrace and incorporate the approach this article proposes. It has not been my purpose to advance an analysis that is attractive for its ease of application or for its failure to challenge accepted and comfortable ways of thinking about equal protection and race. Rather, it is my hope that the preliminary thoughts expressed in the preceding pages will stimulate others to think about racism in a new way and will provoke a discussion of how equal protection doctrine can best incorporate this understanding of racism.

This article has argued that judicial exploration of the cultural meaning of governmental actions with racially discriminatory impact is

323. Bell, Brown v. Board of Education and the Interest-Convergence Dilemma, 93 HaRv. L. REv. 518, 523-24 (1980); see also D. BeLL, supra note 21, at 435-44.

324. See Freeman, supra note 3.

325. See Lawrence, supra note 7, at 839-50; see also Freeman, supra note 3, at 1052-57.

326. See notes $34-35$ supra and accompanying text.

327. See notes $36-38$ supra and accompanying text. 
the best way to discover the unconscious racism of governmental actors. This exploration will be beset by the complexities and inadequacies of social interpretation and buffeted by the head winds of political resistance. Perhaps I am overly optimistic in believing that in the process of this difficult exploration we may discover and understand a collective self-interest that overshadows the multitude of parochial selfinterests the unconscious seeks to disguise and shield. ${ }^{328}$ But of one thing I am certain. A difficult and painful exploration beats death at the hands of the disease. 